\title{
LOS DERECHOS HUMANOS Y EL ORDEN OBJETIVO DE VALORES COMO PARÁMETRO DE CONTROL: LA POSICIÓN DEL VOTO POR ACOGER. COMENTARIO A LA SENTENCIA DEL TRIBUNAL CONSTITUCIONAL QUE RECAE SOBRE LAS NORMAS QUE PERMITEN MODIFICAR UNILATERALMENTE EL PRECIO BASE DEL PLAN DE SALUD*
}

\section{Human RightS AND THE OBJECTIVE ORDER OF VALUES AS A PARAMETER} FOR CONTROL: COMMENT ON THE CONSTITUTIONAL COURT'S

JUDGMENT ON THE NORMS ALLOWING THE UNILATERAL MODIFICATION OF BASIC PRICES OF HEALTH CONTRACTS

Gonzalo Aguilar Cavallo** U. de Valparaíso y U. Andrés Bello - Chile gaguilarch@hotmail.com

\section{INTRODUCCIÓN}

Con fecha 2 de mayo de 2012, el Tribunal Constitucional chileno tuvo la oportunidad, una vez más, de extender su creciente doctrina en materia de derechos sociales, particularmente del derecho a la protección de la salud, a propósito de sendos requerimientos de inaplicabilidad por inconstitucionalidad respecto del inciso tercero del artículo 38 y del artículo 38 bis, ambos de la Ley No 18.933. Como se ha dicho, ésta no es la primera vez que el Tribunal Constitucional se pronuncia sobre los contratos de salud con las Isapres, sobre el derecho a la protección de la salud, sobre el derecho a la seguridad social, sobre el efecto horizontal de los derechos humanos y sobre el progresivo avance de la constitucionalización

\footnotetext{
* Trabajo recibido del 5 de junio de 2013 y aprobado el 8 de enero de 2014.

** Abogado (Chile), Doctor en Derecho (España), Magíster en Relaciones Internacionales (España), Máster en Derechos Humanos y Derecho Humanitario (Francia). Posdoctorado en el Max Planck Institute for Comparative Public Law and International Law (Heidelberg, Alemania). Profesor de Derecho de la Universidad de Valparaíso (Valparaíso, Chile) y de la Universidad Andrés Bello (Santiago, Chile).
} 
del Derecho privado ${ }^{1}$. Una de las enseñanzas más relevantes de los jueces constitucionales es aquella que afirma que "la amplia mayoría de la doctrina nacional y extranjera reconoce que los derechos sociales, llamados también derechos de prestación o de la segunda generación, son tales y no simples declamaciones o meras expectativas, cuya materialización efectiva quede suspendida hasta que las disponibilidades presupuestarias del Estado puedan llevarlos a la práctica"2. Junto con lo anterior, un pilar de esta doctrina del Tribunal Constitucional en materia de derechos sociales la constituye la aseveración de que "resulta ineludible desvanecer la tesis contraria a que los derechos sociales sean realmente tales, aseverando que poner en duda su "practicabilidad" de realización, es una idea confusa, porque esa "reserva de lo posible" lleva a sostener que la Constitución ha de ser "desactivada", a causa de la imposibilidad económica del Estado de darles satisfacción, convirtiendo así en virtuales las cláusulas fundamentales que aseguran su materialización"3.

1 Vid., por ejemplo, Tribunal Constitucional: Requerimiento de inaplicabilidad por inconstitucionalidad de María Ximena Osorio Sagredo respecto del artículo 38 ter de la Ley No 18.933 -introducido por la Ley No 20.015-, que actualmente corresponde al artículo 199 del D.F.L. (Ministerio de Salud) No 1, de 2005, en la causa Rol No 10.913-2008, de la que conoce actualmente, como árbitro arbitrador, el Intendente de Fondos y Seguros de Salud. Rol No 1218-08. Sentencia de fecha 7 de julio de 2009; Tribunal Constitucional: Requerimiento de inaplicabilidad por inconstitucionalidad de Pedro Fernández Bitterlich respecto del artículo 199 del Decreto con Fuerza de Ley (Ministerio de Salud) No 1, de 2005, que fija el texto refundido, coordinado y sistematizado del D.L. No 2.763, de 1979, y de las Leyes $\mathrm{No}^{\circ}$ s. 18.933 y 18.469 , en el recurso de protección ante la Corte de Apelaciones de Santiago en contra de la Isapre Colmena Golden Cross S.A., Rol No 7952-2008, que se encuentra en apelación de la sentencia de primera instancia, de la que conoce la Corte Suprema bajo el Rol de ingreso No 7779-2008. Rol No 1287-08. Sentencia de fecha 8 de septiembre de 2009; Tribunal Constitucional: Proceso iniciado de oficio para decidir sobre la constitucionalidad del artículo 38 ter de la Ley de Isapres y cuya sentencia se publicó en el Diario Oficial el 9 de agosto de 2010. Rol No 1710-10. Sentencia de fecha 6 de agosto de 2010; Tribunal Constitucional: Requerimiento de inaplicabilidad por inconstitucionalidad de Raúl Martínez Castillo respecto de los artículos 38 de la Ley No 18.933, vigente con anterioridad a la Ley No 20.015, en la parte que alude a la tabla de factor etáreo, 38 ter de la misma Ley No $18.933,2^{\circ}$ de la Ley No 20.015 y 199 del D.F.L. No 1 , de 2005, del Ministerio de Salud, en los autos Rol No 20.756-2009 sustanciados ante el Tribunal Arbitral de la Superintendencia de Salud en contra de la Isapre Colmena Golden Cross S.A. Rol No 1572-09. Sentencia de fecha 30 de noviembre de 2010 .

2 Tribunal Constitucional: Requerimiento de inaplicabilidad deducido por Silvia Peña Wasaff respecto del artículo 38 ter de la Ley $N^{o}$ 18.933, conocida como Ley de Isapres, en recurso de protección contra Isapre ING Salud S.A., Rol de Ingreso No 4972-2007, de la Corte de Apelaciones de Santiago. Rol No 976-07. Sentencia de fecha 26 de junio de 2008. Considerando $26^{\circ}$.

3 Tribunal Constitucional: Requerimiento de inaplicabilidad deducido por Silvia Peña Wasaff respecto del artículo 38 ter de la Ley $N^{o}$ 18.933, conocida como Ley de Isapres, en recurso de protección contra Isapre ING Salud S.A., Rol de Ingreso No 4972-2007, de la Corte de Apelaciones de Santiago. Rol No 976-07. Sentencia de fecha 26 de junio de 2008. Considerando $27^{\circ}$. 
En la votación del requerimiento, se produjo empate de votos, por lo que se tuvo por desechado el requerimiento por no haberse alcanzado el quórum constitucional necesario para ser acogido. En efecto, hubo cinco Ministros (Vodanovic, Fernández, Carmona, Viera-Gallo, García) por aprobar y cinco Ministros (Bertelsen, Venegas, Peña, Navarro, Aróstica) por rechazar el requerimiento. Desde la perspectiva procesal, debería entenderse que la doctrina que establece la sentencia es aquella que funda el rechazo del requerimiento, sin perjuicio del voto por acoger que podría asimilarse a una especie de disidencia. Con todo, en esta ocasión los jueces constitucionales que estuvieron por acoger el requerimiento aprovecharon de explayarse en relación a los elementos que rodean al contrato de salud y, en particular, a la permanente penetración del derecho constitucional de los derechos humanos en el Derecho privado.

En resumen, dos particulares presentan un requerimiento de inaplicabilidad por inconstitucionalidad respecto de normas legales que habilitan la modificación unilateral discrecional periódica del precio base del plan de salud, lo que pone en juego, básicamente, las normas constitucionales sobre el derecho a la igualdad, el derecho a la protección de la salud y la seguridad social.

De esta manera, en este conciso comentario, se revisarán brevemente los hechos que motivaron este requerimiento de constitucionalidad, luego se examinarán los argumentos de las partes y, posteriormente, revisaremos los razonamientos del Tribunal. En el análisis del razonamiento del Tribunal nos concentraremos especialmente en el voto por acoger el requerimiento, pero, cuando corresponda, nos referiremos sucintamente a la argumentación del voto por el rechazo del requerimiento. Así, en esta parte, nuestra atención se enfocará singularmente al examen del contenido del derecho a la salud, de los elementos del contrato de salud, de su función social, así como al fenómeno de constitucionalización del Derecho civil, la tensión que ello produce con los principios clásicos de los contratos y el efecto horizontal de los derechos fundamentales.

\section{HeCHOS}

Tal como lo ha señalado el propio Tribunal Constitucional, la requirente Sheila Hasbún señala que, "en diciembre de 1995, a los 24 años de edad, suscribió un contrato de salud con Isapre Colmena Golden Cross S.A., referido al plan Master 2000, con un precio de 4,2 Unidades de Fomento mensuales, que se descomponía en 1,82 unidades de fomento de precio base y un factor de riesgo de 2,3. Agrega que en el año 2010, por decimocuarto año, la Isapre pretende reajustar el precio base de su plan de salud. Expone que es la octava vez que recurre de protección 
para dejar sin efecto esa alza y que de no haber accionado ante la justicia el precio base de su plan, originalmente de 1,82 U.F., hoy sería de 8,24 U.F. Agrega que en razón de la aplicación de los factores de riesgo, si comenzó pagando 4,2 U.F., hoy estaría pagando 16,08". Además, se indica que en "el proceso Rol No 2020-10, el requirente tiene 76 años de edad y señala que hace 25 años suscribió un contrato conjuntamente con su cónyuge, de entonces 42 años, con la Isapre Colmena Golden Cross por el plan Premium 2005, cuyo precio base ha llegado a las 3,23 UF, con un factor de riesgo de 6,0, lo que da un valor de 19,38 UF mensuales, más GES y cobertura catastrófica, lo que arroja un valor total de 20,24 unidades de fomento. Expone que paulatinamente es víctima de una confiscación patrimonial y que se pensionó hace 10 años pagando 171 mil pesos a su Isapre, cifra que hoy llega a 433 mil pesos mensuales, por lo que su patrimonio ha bajado un 1,7\%. Agrega que durante el año 2001 la Isapre consumía el 36\% de su pensión y que hoy ese precio es el 99\% de su pensión, además de lo cual el año 2003 tuvo que aceptar un plan con coberturas menores" 4 .

\section{ARgumentos DE LOS ÓRGANOS CONSTITUCIONALMENTE LEGITIMADOS}

En esta parte resumiremos sucintamente los argumentos sobre el conflicto de constitucionalidad surgido a propósito de sendos recursos de protección interpuestos ante la Corte de Apelaciones de Santiago en contra de Isapre Colmena Golden Cross S.A. y que dieron lugar a requerimientos de inaplicabilidad planteados ante el Tribunal Constitucional.

\section{Argumentos de los requirentes}

Los requirentes hacen suyos los razonamientos del fallo Rol No 976 (caso "Peña Wasaff"), en orden a la fuente constitucional del contrato de salud, sus caracteres y el rol del Estado en el mismo. Además, consideran infringidos los siguientes derechos: "1) La igualdad en dignidad y derechos que se ostentan desde el nacimiento, consagrada en el artículo $1^{\circ}$ de la Constitución Política de la República. 2) La igualdad ante la ley y la interdicción de la discriminación arbitraria del No $2^{\circ}$ del artículo 19 de la Carta Fundamental. 3) El bien común, en la medida

4 Tribunal Constitucional: Requerimiento de inaplicabilidad por inconstitucionalidad presentado por Sheila Hasbún Bernier respecto del inciso tercero del artículo 38 y artículo 38 bis de la Ley $N^{o} 18.933$, al que se acumuló el Rol No 2020-11, requerimiento presentado por Julio Francisco Javier Fuenzalida Asmussen respecto de las mismas normas. Rol No 1856-10. Sentencia de fecha 2 de mayo de 2012, p. 4. 
que la normativa impugnada sólo sirve a los intereses de la Isapre, en desmedro de los derechos fundamentales del afiliado. 4) El derecho de propiedad sobre prestaciones y coberturas contratadas en los años 1995 y 2001, respectivamente, de conformidad al numeral $24^{\circ}$ del artículo 19 de la Constitución Política. 5) El derecho a la elección del sistema público o privado de salud, de conformidad al artículo $19 \mathrm{~N}^{\circ} 9^{\circ}$ de la Carta Fundamental. 6) El derecho a la integridad física y psíquica, amparado por el artículo 19 No $1^{\circ}$ de la Carta Fundamental. 7) El derecho a que la legislación que se va a aplicar en la gestión invocada no vulnere los derechos fundamentales ni la esencia de los mismos, de conformidad al inciso segundo del artículo $5^{\circ}$ y al numeral $26^{\circ}$ del artículo 19 , ambos de la Constitución Política"'.

Junto con ello, los requirentes señalan que "las diferencias de trato por el legislador sólo son admisibles en la medida que sean razonables, proporcionadas y objetivas, según jurisprudencia de este Tribunal y de las Cortes Interamericana y Europea de Derechos Humanos".

Relevante resulta la alegación de los requirentes en cuanto a que "se considera vulnerado el derecho a la protección de la salud, mermado anualmente por el mecanismo de reajuste del precio, haciendo suyo en este sentido lo razonado acerca de este derecho por esta Magistratura en su sentencia Rol No 976 e invocando sentencias de la Corte Suprema que reconocen que un alza desmedida infringe la libertad de elección al forzar la salida del afiliado, en infracción además de la garantía de respeto al contenido esencial del derecho".

\section{Argumentos del requerido}

Por su parte, la Isapre requerida "razona que no hay infracción alguna a las garantías constitucionales invocadas por el requirente y que lo único que corresponde determinar es si la ley ha regulado legítimamente el ejercicio del derecho a la protección de la salud, porque todas las supuestas infracciones a las demás normas constitucionales no podrían sino ser consecuencia de la normativa impugnada. En este marco, expone que el No 9o del artículo 19 de la Carta Fundamental dispone en su inciso tercero que es deber del Estado garantizar la ejecución de las acciones de salud, por prestadores públicos o privados, lo que se

5 Tribunal Constitucional: Requerimiento de inaplicabilidad por inconstitucionalidad presentado por Sheila Hasbún Bernier respecto del inciso tercero del artículo 38 y artículo 38 bis de la Ley $N^{o} 18.933$, al que se acumuló el Rol No 2020-11, requerimiento presentado por Julio Francisco Javier Fuenzalida Asmussen respecto de las mismas normas. Rol No 1856-10. Sentencia de fecha 2 de mayo de 2012, p. 11. 
ejercerá 'en la forma y condiciones que determine la ley', por lo cual delegó esta materia en el legislador, quien puede incluso condicionarla. Agrega que no ocurre en la especie lo constatado por esta Magistratura en su sentencia Rol No 17102010-INC, en orden a que la ley entregó la regulación de una materia propia del legislador a la autoridad administrativa, reiterando lo razonado en la resolución de inadmisibilidad Rol No 1210, en el sentido de que se está en presencia de una materia que debe discutirse en sede de protección y no de inaplicabilidad. Por todo lo expuesto, concluye que el legislador reconoció la necesidad de ajustar los precios, que esta regulación legislativa está amparada por la Carta Fundamental en el inciso tercero del № $9^{\circ}$ de su artículo 19 , que son los jueces del fondo los que deben velar por las garantías constitucionales en el marco del ejercicio de esta facultad, que las Isapres no pueden discriminar al ejercerla, que la Superintendencia revisa las adecuaciones y puede sancionar a las Isapres si no cumplen con la ley y que la reclamante sufrió un alza de sólo un 4\%, pudiendo haber llegado hasta un $12,79 \%$, con un aumento total de 0,43 en 15 años"6.

\section{RAZONAMIENTO DEL TRIBUNAL}

El Tribunal Constitucional comienza su razonamiento señalando que no se ha reunido el quórum exigido para acoger la acción de inaplicabilidad por inconstitucionalidad, de acuerdo con el artículo 93 No 6 de la Constitución, en razón de haberse producido un empate de votos. Por esta razón, el requerimiento culminó por ser rechazado. Consecuentemente, en el desarrollo de su fallo, el Tribunal expone primeramente las consideraciones del voto por rechazar el requerimiento y luego, las que corresponden al voto por acoger el mismo.

Desde la perspectiva del Derecho procesal constitucional chileno, la decisión del Tribunal Constitucional es la que corresponde al voto por rechazar el requerimiento, debido a que -como se ha dicho- no se alcanzó el quórum requerido para acoger. En este caso, la posición contraria, esto es, el voto por acoger el requerimiento, no representa la doctrina que asume la decisión del Tribunal, sin perjuicio de poder considerarlo un voto disidente de relevancia ya que la mitad de los Ministros del Tribunal Constitucional asumen esta postura.

6 Tribunal Constitucional: Requerimiento de inaplicabilidad por inconstitucionalidad presentado por Sheila Hasbún Bernier respecto del inciso tercero del artículo 38 y artículo 38 bis de la Ley $N^{o} 18.933$, al que se acumuló el Rol No 2020-11, requerimiento presentado por Julio Francisco Javier Fuenzalida Asmussen respecto de las mismas normas. Rol No 1856-10. Sentencia de fecha 2 de mayo de 2012, p. 20. 


\section{Voto por rechazar el requerimiento: esta es la doctrina que asume la sentencia del Tribunal}

El voto por rechazar el requerimiento proporciona los siguientes argumentos para rechazarlo:

\subsection{La situación no es comparable ni equivalente a aquella que condujo a la declaración de inconstitucionalidad en el Rol No 1710}

"Que, a diferencia de la facultad que la ley confería a las Isapres para ajustar los precios de los planes de salud por el simple transcurso del tiempo, reflejado en el aumento de la edad de los beneficiarios, situación que fue sancionada con la declaración de su inconstitucionalidad, pronunciada por este Tribunal mediante sentencia recaída en los autos Rol No 1710, por violatoria de la igualdad ante la ley y por no resultar integralmente compatible con el respeto de los derechos de protección a la salud y de la seguridad social, asegurados por la Carta Fundamental, en el presente caso se trata de una situación diferente, pues, en conformidad a los preceptos legales ahora cuestionados, la revisión de los contratos debe obedecer a cambios efectivos y verificables de los precios de las prestaciones cubiertas por el plan, que deben justificarse de manera cabal, pormenorizada y racional. No es admisible, en consecuencia, extrapolar al caso que ahora nos ocupa los razonamientos tenidos a la vista por esta Magistratura para resolver un conflicto por completo diferente, como lo fue la derogación de los denominados factores etáreos;”7.

\subsection{Ahora, la facultad de las Isapres se encuentra razonablemente delimitada por el legislador}

"Que, en efecto, la facultad que los preceptos legales ahora cuestionados atribuyen a las Isapres para ajustar el precio base de los planes de salud se encuentra, a nuestro juicio, razonablemente delimitada por el propio legislador, de manera que no configura una potestad de reforma unilateral del precio de los contratos de salud sino, más bien, un mecanismo destinado a mantener la equivalencia de

\footnotetext{
7 Tribunal Constitucional: Requerimiento de inaplicabilidad por inconstitucionalidad presentado por Sheila Hasbun Bernier respecto del inciso tercero del artículo 38 y artículo 38 bis de la Ley No 18.933, al que se acumuló el Rol No 2020-11, requerimiento presentado por Julio Francisco Javier Fuenzalida Asmussen respecto de las mismas normas. Rol No 1856-10. Sentencia de fecha 2 de mayo de 2012. Voto por el rechazo del requerimiento. Considerando $3^{\circ}$.
} 
las prestaciones de los contratantes, a fin de precaver que, con su aplicación, se produzca un enriquecimiento sin causa de una de ellas en perjuicio de la otra;"8.

\subsection{La ley establece prohibiciones severas de discriminación y establece reglas precisas a las que debe sujetarse las modificaciones al plan, cuyo cumplimiento se encomienda fiscalizar a la Superintendencia respectiva}

"Que, de esta forma, en relación al ejercicio de la facultad, dichos preceptos legales no sólo establecen prohibiciones severas de discriminación o de estar motivado por el estado de salud de afiliados o cargas, prohibiciones cuya infracción da lugar a que el contrato se entienda vigente en las mismas condiciones generales, sin perjuicio de las demás sanciones que se puedan aplicar; sino que, también, establecen reglas precisas a las que debe sujetarse, cuyo cumplimiento se encomienda fiscalizar a la Superintendencia respectiva, pudiendo esta repartición dejar sin efecto las alzas de precios que no se ajusten a ellas, y aplicar, además, sanciones que deben ser informadas al público en general. Lo anterior, sin perjuicio de la revisión jurisdiccional de las alzas, activa y masivamente practicada por los afiliados a las Isapres, cuando se sienten agraviados en sus derechos por alzas injustificadas;"'.

\subsection{La doctrina de la revisión jurisdiccional del ejercicio de la facultad de ajustar el precio base de los planes de salud}

Esta doctrina derivada de la revisión judicial "da cuenta de una afincada doctrina conforme a la cual ella debe ejercitarse de manera razonable y equitativa, y obedecer a un cambio efectivo y comprobable del valor económico de las prestaciones médicas, en razón de una alteración sustancial de sus costos y no a

\footnotetext{
8 Tribunal Constitucional: Requerimiento de inaplicabilidad por inconstitucionalidad presentado por Sheila Hasbún Bernier respecto del inciso tercero del artículo 38 y artículo 38 bis de la Ley No 18.933, al que se acumuló el Rol No 2020-11, requerimiento presentado por Julio Francisco Javier Fuenzalida Asmussen respecto de las mismas normas. Rol No 1856-10. Sentencia de fecha 2 de mayo de 2012. Voto por el rechazo del requerimiento. Considerando $4^{\circ}$.

9 Tribunal Constitucional: Requerimiento de inaplicabilidad por inconstitucionalidad presentado por Sheila Hasbun Bernier respecto del inciso tercero del artículo 38 y artículo 38 bis de la Ley $N^{o}$ 18.933, al que se acumuló el Rol No 2020-11, requerimiento presentado por Julio Francisco Javier Fuenzalida Asmussen respecto de las mismas normas. Rol No 1856-10. Sentencia de fecha 2 de mayo de 2012. Voto por el rechazo del requerimiento. Considerando $5^{\circ}$.
} 
un simple aumento debido a fenómenos inflacionarios o a la frecuencia en el uso del sistema" 10 .

\subsection{Nada impide cuestionar en sede de protección la racionalidady justicia de la modificación del precio base}

Igualmente, los jueces constitucionales que estuvieron por rechazar señalaron "Que, por lo mismo, nada impide cuestionar y revisar en dicha sede de protección la racionalidad y justicia de la modificación del precio base, a la vez que determinar si al efectuarse la misma se actuó de manera fundada o si -por el contrario- fue resultado de una situación que importe en el hecho una diferenciación arbitraria o manifiestamente desproporcionada para la parte contratante, en atención a la naturaleza propia de contrato de adhesión que reviste el seguro de salud previsional. La propia requirente ha cuestionado el ejercicio de dicha facultad en un recurso de protección, el que constituye por lo demás la gestión pendiente que motivó esta presentación;"11.

\subsection{La declaración de inaplicabilidad de la disposición produciria un efecto contrario a la Carta Politica}

De manera muy sucinta, una de las consideraciones del voto por rechazar el requerimiento que vale la pena retener en este análisis es la siguiente: "Que los Ministros que suscriben este voto no pueden dejar adicionalmente de tener en consideración las consecuencias, para el caso concreto, que podría ocasionar una declaración de inaplicabilidad como la impetrada en estos autos. En efecto, como lo ha sostenido esta Magistratura, 'constituye un principio elemental de prudencia constitucional el que el Tribunal Constitucional debe abstenerse de declarar la inapli-

\footnotetext{
10 Tribunal Constitucional: Requerimiento de inaplicabilidad por inconstitucionalidad presentado por Sheila Hasbún Bernier respecto del inciso tercero del artículo 38 y artículo 38 bis de la Ley No 18.933, al que se acumuló el Rol No 2020-11, requerimiento presentado por Julio Francisco Javier Fuenzalida Asmussen respecto de las mismas normas. Rol No 1856-10. Sentencia de fecha 2 de mayo de 2012. Voto por el rechazo del requerimiento. Considerando $6^{\circ}$.

11 Tribunal Constitucional: Requerimiento de inaplicabilidad por inconstitucionalidad presentado por Sheila Hasbuin Bernier respecto del inciso tercero del artículo 38 y artículo 38 bis de la Ley $N^{o}$ 18.933, al que se acumuló el Rol No 2020-11, requerimiento presentado por Julio Francisco Javier Fuenzalida Asmussen respecto de las mismas normas. Rol No 1856-10. Sentencia de fecha 2 de mayo de 2012. Voto por el rechazo del requerimiento. Considerando $9^{\circ}$.
} 
cabilidad por inconstitucionalidad de una norma en aquellos casos en que ello pudiera engendrar una lesión de mayor envergadura constitucional' (Rol No 616/2007)"12.

Y, luego, a manera explicativa, agrega: "Que, en el caso concreto, la inaplicabilidad de la disposición produciría un efecto contrario a la Carta Política, desde que tal declaración supondría que en la relación contractual entre las partes se aplicara la legislación anterior a la normativa aprobada el año 2005, la que a todas luces le resulta más perjudicial al afiliado de la institución de salud previsional, al dejar entregada dicha materia a la libre determinación de las partes"13.

\section{Voto por acoger el requerimiento: posición que no asume el Tribunal}

Con todo, la parte que ha retenido nuestra atención y que será netamente más desarrollada en este comentario corresponde al voto por acoger el requerimiento, en tanto este voto se explaya en cuanto al contenido del derecho de salud (1), en lo que respecta a los rasgos esenciales del contrato de salud llamado "previsional" (2), en la esfera de la constitucionalización del Derecho Civil (3) y en el ámbito de la eficacia entre particulares de los derechos fundamentales (4). Adicionalmente, nos referiremos a llamativos de esta decisión constitucional, por un lado, al uso de derecho internacional o comparado (5), y por otro lado, a la interpretación constitucional vis-à-vis la interpretación en derechos humanos (6).

\subsection{Contenido y contornos del derecho a la salud}

El voto por acoger la inaplicabilidad vincula el derecho a la protección de la salud a los derechos de seguridad social. El voto considera el derecho de protección de la salud como integrante de los derechos de seguridad social. Y cabe preguntarse si el derecho de protección de la salud forma parte de los denominados derechos de seguridad social o si se trata de dos derechos distintos aunque

12 Tribunal Constitucional: Requerimiento de inaplicabilidad por inconstitucionalidad presentado por Sheila Hasbuin Bernier respecto del inciso tercero del artículo 38 y artículo 38 bis de la Ley $N^{o}$ 18.933, al que se acumuló el Rol No 2020-11, requerimiento presentado por Julio Francisco Javier Fuenzalida Asmussen respecto de las mismas normas. Rol No 1856-10. Sentencia de fecha 2 de mayo de 2012. Voto por el rechazo del requerimiento. Considerando $11^{\circ}$.

13 Tribunal Constitucional: Requerimiento de inaplicabilidad por inconstitucionalidad presentado por Sheila Hasbuin Bernier respecto del inciso tercero del artículo 38 y artículo 38 bis de la Ley $N^{o} 18.933$, al que se acumuló el Rol No 2020-11, requerimiento presentado por Julio Francisco Javier Fuenzalida Asmussen respecto de las mismas normas. Rol No 1856-10. Sentencia de fecha 2 de mayo de 2012. Voto por el rechazo del requerimiento. Considerando $12^{\circ}$. 
interdependientes, interrelacionados e indivisibles. Sobre todo, porque dentro de su argumentación, los jueces constitucionales también destacan expresamente que "la íntima vinculación que tiene asimismo la seguridad social con el derecho a la protección de la salud, asegurado por la Constitución en el No 9 de su artículo 19, por cuanto, como ya vimos, la carencia de dicho estado constituye una contingencia que la sociedad debe preocuparse de cubrir"14. De hecho, desde el punto de vista contractual, los jueces constitucionales afirman que "el contrato de salud previsional se inscribe dentro del ámbito de la seguridad social"15. Por esta razón, los jueces constitucionales se refieren en el contexto de la salud y de la seguridad social a un servicio público o de finalidad pública, a las "necesidades impostergables de las personas", y al "carácter socialmente imprescindible" de dichos bienes, prestaciones y servicios ${ }^{16}$, o bien, a "la provisión de un servicio vital del que no pueden prescindir quienes los celebran"17. Estas necesidades básicas de todo ser humano y, por tanto, bienes públicos, se encuentran amparados por los derechos humanos de protección de la salud y a la seguridad social que todos - de acuerdo con el artículo $6^{\circ}$ de la Constitución chilena- deben respetar, proteger y garantizar, tanto autoridades estatales como particulares.

En concordancia con lo anteriormente señalado, cabe igualmente reiterar la norma contenida en el artículo $1^{\circ}$ inciso $4^{\circ}$ de la Constitución chilena, en el

14 Tribunal Constitucional: Requerimiento de inaplicabilidad por inconstitucionalidad presentado por Sheila Hasbuin Bernier respecto del inciso tercero del artículo 38 y artículo 38 bis de la Ley $N^{o} 18.933$, al que se acumuló el Rol No 2020-11, requerimiento presentado por Julio Francisco Javier Fuenzalida Asmussen respecto de las mismas normas. Rol No 1856-10 (2020-11)-INA. Sentencia de fecha 2 de mayo de 2012. Voto por acoger el requerimiento, considerando $33^{\circ}$.

15 Tribunal Constitucional: Requerimiento de inaplicabilidad por inconstitucionalidad presentado por Sheila Hasbuin Bernier respecto del inciso tercero del artículo 38 y artículo 38 bis de la Ley $N^{o} 18.933$, al que se acumuló el Rol No 2020-11, requerimiento presentado por Julio Francisco Javier Fuenzalida Asmussen respecto de las mismas normas. Rol No 1856-10 (2020-11)-INA. Sentencia de fecha 2 de mayo de 2012. Voto por acoger el requerimiento, considerando $25^{\circ}$.

16 Tribunal Constitucional: Requerimiento de inaplicabilidad por inconstitucionalidad presentado por Sheila Hasbuin Bernier respecto del inciso tercero del artículo 38 y artículo 38 bis de la Ley $N^{o} 18.933$, al que se acumuló el Rol No 2020-11, requerimiento presentado por Julio Francisco Javier Fuenzalida Asmussen respecto de las mismas normas. Rol No 1856-10 (2020-11)-INA. Sentencia de fecha 2 de mayo de 2012. Voto por acoger el requerimiento, considerando $34^{\circ}$.

17 Tribunal Constitucional: Requerimiento de inaplicabilidad por inconstitucionalidad presentado por Sheila Hasbún Bernier respecto del inciso tercero del artículo 38 y artículo 38 bis de la Ley $N^{\circ} 18.933$, al que se acumuló el Rol No 2020-11, requerimiento presentado por Julio Francisco Javier Fuenzalida Asmussen respecto de las mismas normas. Rol No 1856-10 (2020-11)-INA. Sentencia de fecha 2 de mayo de 2012. Voto por acoger el requerimiento, considerando $24^{\circ}$. 
sentido que afirma como deber del Estado "dar protección a la población y a la familia". Este deber primordial del Estado se encuentra en armonía con otro que constituye la piedra angular que instaura el modelo constitucional actual. Nos referimos a la norma del artículo $1^{\circ}$ inciso $3^{\circ}$ de la Constitución chilena que afirma que es deber del Estado "contribuir a crear las condiciones sociales que permitan a todos y a cada uno de los integrantes de la comunidad nacional su mayor realización espiritual y material posible, con pleno respeto a los derechos y garantías que esta Constitución establece”.

Los derechos humanos a la protección de la salud y el derecho humano a la seguridad social se deberían entender precisamente en este contexto. Ahora bien, cabe consignar respecto del primero de estos derechos humanos involucrados, que un enfoque mucho más certero e inclusivo es el de comprender el derecho a la salud como el derecho de todas las personas a disfrutar del más alto nivel posible de salud física y mental ${ }^{18}$. En este contexto, de acuerdo con la Observación General No 14, el Comité de Derechos Económicos, Sociales y Culturales ha indicado que "el derecho a la salud debe entenderse como un derecho al disfrute de toda una gama de facilidades, bienes, servicios y condiciones necesarios para alcanzar el más alto nivel posible de salud"19.

Consecuentemente, a la luz de estos valores, principios y normas de carácter constitucional, debe leerse, comprenderse e interpretarse todo el ordenamiento jurídico estatal. Y "[e]llo, es relevante pues el contrato de salud no es un mero contrato de seguro regido por la autonomía de la voluntad, sino un contrato en el que se comprometen derechos como a la seguridad social y a la salud"20.

18 Comité de Derechos Económicos, Sociales y Culturales: Observación general No 14 (2000). El derecho al disfrute del más alto nivel posible de salud (artículo 12 del Pacto Internacional de Derechos Económicos, Sociales y Culturales). Doc. N.U. E/C.12/2000/4, 11 de agosto de 2000.

19 Comité de Derechos Económicos, Sociales y Culturales: Observación general No 14 (2000). El derecho al disfrute del más alto nivel posible de salud (artículo 12 del Pacto Internacional de Derechos Económicos, Sociales y Culturales). Doc. N.U. E/C.12/2000/4, 11 de agosto de 2000, para. 9.

20 Tribunal Constitucional: Requerimiento de inaplicabilidad por inconstitucionalidad presentado por Sheila Hasbuin Bernier respecto del inciso tercero del artículo 38 y artículo 38 bis de la Ley $N^{\circ} 18.933$, al que se acumuló el Rol No 2020-11, requerimiento presentado por Julio Francisco Javier Fuenzalida Asmussen respecto de las mismas normas. Rol No 1856-10 (2020-11)-INA. Sentencia de fecha 2 de mayo de 2012. Voto por acoger el requerimiento, considerando $33^{\circ}$. "Que, en este mismo orden de consideraciones, resulta imprescindible indicar que el contrato que celebra un afiliado con una determinada Isapre no equivale a un mero seguro individual de salud, regido por el principio de autonomía de la voluntad, pues opera en relación con un derecho garantizado constitucionalmente a las personas en el marco de la seguridad social y en que la entidad privada que otorga el seguro, tiene asegurada, por ley, una cotización, o sea, un ingreso garantizado. Así, las normas que regulan esta relación jurídica son de orden público". Tribunal Constitucional: Proceso 
De acuerdo con el voto por acoger la inaplicabilidad, la ley permite un alza unilateral de los precios de los planes de salud sin fijar sus extremos, esto es, sin fijar un máximo de las alzas permitidas de tal manera que no se vulneren derechos fundamentales. Así, los jueces constitucionales han señalado que, "al no establecerse límites precisos, se incumple el deber de protección de la salud que pesa sobre el Estado"21. No fijando el máximo de las alzas permitidas, se deja entregada la determinación del alza de precios a la libre autonomía de la libertad contractual de las partes. Y la falta de igualdad real entre las partes afecta la capacidad y la libertad negociadora entre ellas, lo que en un contrato como el de salud, afecta asimismo otros derechos humanos. De hecho, los propios jueces constitucionales admiten que en el contrato de salud entre la Isapre y el particular cotizante "el punto de partida en el juicio de igualdad no es precisamente el de un poder equivalente" 22 .

En efecto, la abismante diferencia entre el poder de la Isapre y el poder negociador del afiliado acarrea como efecto ya sea o el alza de los precios de los planes o la disminución en las prestaciones de salud, en ambos casos con perjuicio de los derechos del afiliado. De este modo, se ha sostenido que "la vulneración de la igualdad ante la ley acarrea en este caso una afectación sustantiva del derecho de protección de la salud"23. Tomando debidamente en cuenta esto último, los jueces constitucionales han concluido que "[e]stas situaciones constituyen un efecto inconstitucional de las normas aludidas porque obligan al usuario a renun-

iniciado de oficio para decidir sobre la constitucionalidad del artículo 38 ter de la Ley de Isapres y cuya sentencia se publicó en el Diario Oficial el 9 de agosto de 2010. Rol No 1710-10. Sentencia de fecha 6 de agosto de 2010. Considerando $154^{\circ}$.

21 Tribunal Constitucional: Requerimiento de inaplicabilidad por inconstitucionalidad presentado por Sheila Hasbún Bernier respecto del inciso tercero del artículo 38 y artículo 38 bis de la Ley $N^{o} 18.933$, al que se acumuló el Rol No 2020-11, requerimiento presentado por Julio Francisco Javier Fuenzalida Asmussen respecto de las mismas normas. Rol No 1856-10 (2020-11)-INA. Sentencia de fecha 2 de mayo de 2012. Voto por acoger el requerimiento, considerando $28^{\circ}$.

22 Tribunal Constitucional: Requerimiento de inaplicabilidad por inconstitucionalidad presentado por Sheila Hasbuin Bernier respecto del inciso tercero del artículo 38 y artículo 38 bis de la Ley $N^{o} 18.933$, al que se acumuló el Rol No 2020-11, requerimiento presentado por Julio Francisco Javier Fuenzalida Asmussen respecto de las mismas normas. Rol No 1856-10 (2020-11)-INA. Sentencia de fecha 2 de mayo de 2012. Voto por acoger el requerimiento, considerando $13^{\circ}$.

23 Tribunal Constitucional: Requerimiento de inaplicabilidad por inconstitucionalidad presentado por Sheila Hasbún Bernier respecto del inciso tercero del artículo 38 y artículo 38 bis de la Ley $N^{\circ} 18.933$, al que se acumuló el Rol No 2020-11, requerimiento presentado por Julio Francisco Javier Fuenzalida Asmussen respecto de las mismas normas. Rol No 1856-10 (2020-11)-INA. Sentencia de fecha 2 de mayo de 2012. Voto por acoger el requerimiento, considerando $27^{\circ}$. 
ciar a derechos fundamentales, en circunstancias de que tal renuncia vulneraría principios constitucionales" 24 .

El voto por acoger el requerimiento describe someramente el contenido de lo que en nuestra Constitución se denomina el derecho a la protección de la salud. En este contexto, el voto se refiere a libertades, derechos y obligaciones del Estado. Dentro de las libertades que enumera menciona la libertad de elección del sistema de salud, sea éste privado o estatal. En cuanto a los derechos, se refiere (1) al derecho que tienen todas las personas a la "protección de la salud", tanto en lo relativo a su promoción como a su protección y recuperación. Del mismo modo, alude (2) al derecho a un acceso libre e igualitario a las acciones de salud, sea a través de instituciones públicas o privadas. Por último, desde el punto de vista de las obligaciones, el voto recuerda (1) el deber del Estado de garantizar la ejecución de las acciones de salud sea a través de instituciones públicas o privadas. También alude (2) al deber del Estado de coordinar y controlar las acciones de salud $^{25}$. En este caso, dejar entregado a la autonomía de la voluntad y a la libertad de las partes la fijación de las condiciones del contrato, tales como sus mecanismos de reajustabilidad, aumenta el desequilibrio inicial entre los co-contratantes arrojando como resultado una afectación seria y grave del goce efectivo del derecho a la salud. Si el Estado y la ley permiten esta situación, entonces no se cumple con el mandato constitucional de garantizar la ejecución de las acciones de salud y el Estado no cumple con la tutela de este derecho que la Constitución le exige ${ }^{26}$.

24 Tribunal Constitucional: Requerimiento de inaplicabilidad por inconstitucionalidad presentado por Sheila Hasbuin Bernier respecto del inciso tercero del artículo 38 y artículo 38 bis de la Ley $N^{o} 18.933$, al que se acumuló el Rol No 2020-11, requerimiento presentado por Julio Francisco Javier Fuenzalida Asmussen respecto de las mismas normas. Rol No 1856-10 (2020-11)-INA. Sentencia de fecha 2 de mayo de 2012. Voto por acoger el requerimiento, considerando $32^{\circ}$.

25 Tribunal Constitucional: Requerimiento de inaplicabilidad por inconstitucionalidad presentado por Sheila Hasbuin Bernier respecto del inciso tercero del artículo 38 y artículo 38 bis de la Ley $N^{o} 18.933$, al que se acumuló el Rol No 2020-11, requerimiento presentado por Julio Francisco Javier Fuenzalida Asmussen respecto de las mismas normas. Rol No 1856-10 (2020-11)-INA. Sentencia de fecha 2 de mayo de 2012. Voto por acoger el requerimiento, considerando $28^{\circ}$.

26 Tribunal Constitucional: Requerimiento de inaplicabilidad por inconstitucionalidad presentado por Sheila Hasbuin Bernier respecto del inciso tercero del artículo 38 y artículo 38 bis de la Ley No 18.933, al que se acumuló el Rol No 2020-11, requerimiento presentado por Julio Francisco Javier Fuenzalida Asmussen respecto de las mismas normas. Rol No 1856-10 (2020-11)-INA. Sentencia de fecha 2 de mayo de 2012. Voto por acoger el requerimiento, considerando $35^{\circ}$. "Que en el inciso cuarto del numeral $9^{\circ}$ de su artículo 19, la Constitución faculta a la ley para establecer 'cotizaciones obligatorias', las que son administradas por 'instituciones públicas $o$ privadas. Se les asegura, por tanto, a las Isapres, un ingreso constante. Frente a esa regla el legislador se encuentra obligado a ponderar la obligación del trabajador (afiliado-cotizante) de pagar tales cotizaciones 
En este contexto, los jueces constitucionales afirman que la forma y condiciones que fije la ley para el acceso y ejecución de las acciones de salud tienen dos límites generales. Por un lado, no pueden afectar o lesionar este derecho a la protección de la salud en su esencia (1) y, por otro, debe procurar un acceso igualitario de todos a las acciones de salud (2) 27 .

Un aumento de los precios en los planes de salud sin ninguna consideración a las personas y a sus necesidades elementales -tales como su estado de salud-puede conducir a anular la capacidad económica de las personas de elección del sistema de salud y, en definitiva, a "una completa imposibilidad de costearlos, ocasionando la indignidad que ello significa para el transcurrir de sus vidas y la evidencia de la falta de concreción de la obligación que el texto de la Constitución le asigna al Estado para dirigir su acción a garantizar el acceso de todos los habitantes al goce de prestaciones básicas uniformes" (STC Rol No 1710, considerando $160^{\circ}$ )"28.

\subsection{Contrato de salud}

En esta parte nos referiremos a distintos aspectos clave que la jurisprudencia del Tribunal Constitucional ha ido acuñando respecto del contrato de salud. En este contexto, mencionaremos el rango constitucional de este contrato y el carácter de orden público de las normas que lo rigen. Consecuentemente, en segundo lugar, nos referiremos a los elementos del contrato que están fuera de la disposición de las partes. En tercer lugar, mencionaremos la especial articulación entre el principio igualdad y de libertad contractual. Por último, explicaremos, en tanto contrato de

obligatorias y, al mismo tiempo, propender al cumplimiento del deber de asegurar la protección de la salud', previsto en el inciso primero de la misma disposición constitucional. No obstante, el mecanismo de reajustabilidad definido por el legislador en esta materia genera un desequilibrio entre el cobro de las cotizaciones y la protección del derecho a la salud, que deja a este último sin la tutela que la Constitución exige". Tribunal Constitucional: Proceso iniciado de oficio para decidir sobre la constitucionalidad del artículo 38 ter de la Ley de Isapres y cuya sentencia se publicó en el Diario Oficial el 9 de agosto de 2010. Rol No 171010. Sentencia de fecha 6 de agosto de 2010. Considerando $156^{\circ}$.

27 Tribunal Constitucional: Requerimiento de inaplicabilidad por inconstitucionalidad presentado por Sheila Hasbuin Bernier respecto del inciso tercero del artículo 38 y artículo 38 bis de la Ley $N^{o} 18.933$, al que se acumuló el Rol No 2020-11, requerimiento presentado por Julio Francisco Javier Fuenzalida Asmussen respecto de las mismas normas. Rol No 1856-10 (2020-11)-INA. Sentencia de fecha 2 de mayo de 2012. Voto por acoger el requerimiento, considerando $30^{\circ}$.

28 Tribunal Constitucional: Requerimiento de inaplicabilidad por inconstitucionalidad presentado por Sheila Hasbún Bernier respecto del inciso tercero del artículo 38 y artículo 38 bis de la Ley $N^{\circ} 18.933$, al que se acumuló el Rol No 2020-11, requerimiento presentado por Julio Francisco Javier Fuenzalida Asmussen respecto de las mismas normas. Rol No 1856-10 (2020-11)-INA. Sentencia de fecha 2 de mayo de 2012. Voto por acoger el requerimiento, considerando $35^{\circ}$. 
orden público y de rango constitucional, la determinante función social que cumple el mismo.

\subsubsection{Contrato de orden público y de rango constitucional}

Los jueces constitucionales han acogido en este sentido la doctrina que correctamente ha elaborado la Corte Suprema relativa a que el contrato de salud "reviste características de orden público y jerarquía constitucional" 29 . Indudablemente que este carácter de orden público que se le asigna a un acuerdo de voluntades y la jerarquía constitucional -la máxima jerarquía dentro de la doctrina clásica de las fuentes formales del derecho- no se deben al contrato en sí mismo, sino más bien, a la entidad de la salud y sus prestaciones como bien público de carácter constitucional y, consecuentemente, al objeto y fin del contrato. En este mismo sentido, el voto por acoger el requerimiento ha afirmado que "el objeto de dichos contratos es la provisión de un servicio vital del que no pueden prescindir quienes los celebran; su finalidad no es garantizar a todo evento la expectativa de rentabilidad de los aseguradores privados sino el acceso efectivo de las personas a la protección de su salud y a la seguridad social" 30 . En efecto, los jueces constitucionales culminan esta caracterización de los contenidos del contrato de salud entre un cotizante y una Isapre calificándolo como "un contrato de adhesión relativo al ejercicio de un derecho constitucional"31. Si esto es así respecto de la salud en cuanto bien público básico, el mismo razonamiento debería operar respecto de la educación, la alimentación, la vivienda, etc.

29 Tribunal Constitucional: Requerimiento de inaplicabilidad por inconstitucionalidad presentado por Sheila Hasbún Bernier respecto del inciso tercero del artículo 38 y artículo 38 bis de la Ley No 18.933, al que se acumuló el Rol No 2020-11, requerimiento presentado por Julio Francisco Javier Fuenzalida Asmussen respecto de las mismas normas. Rol No 1856-10 (2020-11)-INA. Sentencia de fecha 2 de mayo de 2012. Voto por acoger el requerimiento, considerando $41^{\circ}$; Corte Suprema: Calderón Rivero, Patricia Mercedes contra Colmena Golden Cross S.A. Recurso de Protección. Rol No 192-2011. Sentencia de fecha 28 de enero de 2011. Considerando $4^{\circ}$; Corte Suprema: Pino Acosta, Cristián contra Colmena Golden Cross S.A. Recurso de Protección. Rol No 601-2011. Sentencia de fecha 28 de enero de 2011. Considerando $5^{\circ}$.

30 Tribunal Constitucional: Requerimiento de inaplicabilidad por inconstitucionalidad presentado por Sheila Hasbuin Bernier respecto del inciso tercero del artículo 38 y artículo 38 bis de la Ley $N^{o} 18.933$, al que se acumuló el Rol No 2020-11, requerimiento presentado por Julio Francisco Javier Fuenzalida Asmussen respecto de las mismas normas. Rol No 1856-10 (2020-11)-INA. Sentencia de fecha 2 de mayo de 2012. Voto por acoger el requerimiento, considerando $24^{\circ}$.

31 Tribunal Constitucional: Requerimiento de inaplicabilidad por inconstitucionalidad presentado por Sheila Hasbuin Bernier respecto del inciso tercero del artículo 38 y artículo 38 bis de la Ley $N^{o} 18.933$, al que se acumuló el Rol No 2020-11, requerimiento presentado por Julio Francisco Javier Fuenzalida Asmussen respecto de las mismas normas. Rol No 1856-10 (2020-11)-INA. Sentencia de fecha 2 de mayo de 2012. Voto por acoger el requerimiento, considerando $14^{\circ}$. 
El Tribunal Constitucional ha calificado la naturaleza de los contratos de salud de acuerdo con los escasos elementos mínimos que, a propósito del derecho a la protección de la salud, la Constitución chilena entrega. De este modo ha señalado: "El constituyente quiso consagrar ciertos elementos de dicho acuerdo de voluntades, dado el impacto que éste tiene en la vida de las personas. Esos elementos tienen que ver con la posibilidad de las Isapres de prestar acciones de salud (artículo 19 No $^{\circ}$ ), con la opción del cotizante para elegir entre el sistema estatal o privado (artículo 19 $N^{\circ} 9^{\circ}$ ), con la cotización obligatoria (artículo $19 N^{\circ} 9^{\circ}$ ) y con el control por el Estado de las acciones relacionadas con la salud (artículo $19 \mathrm{~N}^{\circ} 9^{\circ}$ )"32.

Así, el contrato de salud es un acuerdo de voluntades con elementos especiales que el legislador se ha encargado de regular: "Éste es un contrato forzoso (artículo 184), de plazo indefinido (artículos 189 y 197), que no puede dejarse sin efecto durante su vigencia, salvo por incumplimiento de sus obligaciones o de mutuo acuerdo entre las partes (artículo 197), de contenido mínimo (artículo 189) e indisponible (artículo 189). En síntesis, 'desde el punto de vista de este Tribunal, es un contrato de tracto sucesivo, de orden público y distinto a un contrato de seguro propio del derecho privado" 33 .

32 Tribunal Constitucional: Requerimiento de inaplicabilidad por inconstitucionalidad presentado por Sheila Hasbún Bernier respecto del inciso tercero del artículo 38 y artículo 38 bis de la Ley $N^{\circ} 18.933$, al que se acumuló el Rol No 2020-11, requerimiento presentado por Julio Francisco Javier Fuenzalida Asmussen respecto de las mismas normas. Rol No 1856-10 (2020-11)-INA. Sentencia de fecha 2 de mayo de 2012. Voto por acoger el requerimiento, considerando $10^{\circ}$. "Que, en segundo lugar, este Tribunal ha caracterizado al contrato de salud previsional en las ya referidas decisiones previas. Estas reiteran o subrayan algunos elementos del contrato ya definidos en la ley. En ella, el contrato es caracterizado como un contrato forzoso (artículo 184), de plazo indefinido (artículos 189 y 197), que no puede dejarse sin efecto durante su vigencia, salvo por incumplimiento de sus obligaciones o de mutuo acuerdo (artículo 197), de contenido mínimo (artículo 189) e indisponible (artículo 189). El involucramiento de esta Magistratura en la ponderación de un contrato obedece a que el contrato de salud previsional contiene elementos regulados en la Constitución, como no sucede con otros contratos. El constituyente quiso consagrar ciertos elementos de dicho acuerdo de voluntades, dado el impacto que éste tiene en la vida de las personas. Esos elementos tienen que ver con la posibilidad de las Isapres de prestar acciones de salud (artículo 19 No $^{\circ}$ ), con la opción del cotizante para elegir entre el sistema estatal o privado (artículo 19 No $9^{\circ}$ ), con la cotización obligatoria (artículo 19 No $9^{\circ}$ ) y con el control por el Estado de las acciones relacionadas con la salud (artículo 19 No $9^{\circ}$ )". Tribunal Constitucional: Requerimiento de inaplicabilidad por inconstitucionalidad de Raúl Martínez Castillo respecto de los artículos 38 de la Ley $N^{o}$ 18.933, vigente con anterioridad a la Ley $N^{\circ} 20.015$, en la parte que alude a la tabla de factor etáreo, 38 ter de la misma Ley $N^{o} 18.933,2^{\circ}$ de la Ley $N^{o} 20.015$ y 199 del D.F.L. No 1, de 2005, del Ministerio de Salud, en los autos Rol No 20.756-2009 sustanciados ante el Tribunal Arbitral de la Superintendencia de Salud en contra de la Isapre Colmena Golden Cross S.A. Rol No 1572-09. Sentencia de fecha 30 de noviembre de 2010. Considerando $36^{\circ}$.

33 Tribunal Constitucional: Requerimiento de inaplicabilidad por inconstitucionalidad presentado por Sheila Hasbuin Bernier respecto del inciso tercero del artículo 38 y artículo 38 bis de la Ley No 18.933, al que se acumuló 
Discrepamos de la opinión de que el constituyente quiso consagrar ciertos elementos del contrato de salud, sino más bien simplemente el constituyente reconoció escasos elementos mínimos propios del derecho a la salud. Luego, los jueces constitucionales aluden a que el legislador ha regulado - de conformidad con estos contenidos mínimos constitucionales- los elementos especiales de este contrato de salud y que difieren de la dimensión de un contrato sólo regido por la autonomía de la voluntad.

Frente a esta afirmación, surge la pregunta: ¿hoy en día cabe razonar sobre la base de contratos entregados exclusivamente a la autonomía de la voluntad? ¿El parámetro de interpretación conforme a la Constitución no obliga a los operadores jurídicos a tomar en consideración siempre las normas constitucionales, especialmente aquellas referidas a derechos humanos? ¿Podría decirse que esto tendría como consecuencia que todo contrato o acuerdo de voluntades está sujeto al respeto, protección y garantía de los derechos humanos? ¿Podría significar esto que ni aun invocando el principio de la autonomía de la voluntad y de la libertad de contratación, por medio de ese acuerdo de voluntades se podrían vulnerar los derechos humanos? Si la respuesta a esta pregunta fuera efectiva, ello significaría que todos los acuerdos de voluntad están condicionados en su validez al respeto, protección y garantía de los derechos humanos.

Quizá en el contrato de salud con la Isapre esto último resalta más, porque se trata de un acuerdo de voluntades cuyo objeto y fin es la protección y garantía de la salud, id est, un derecho fundamental en sí mismo. En efecto, los jueces constitucionales han sostenido que "se trata de una relación sostenida en derechos fundamentales" 34 . En realidad y más claramente, los jueces constitucionales han sostenido que el contrato de salud en cuanto relación contractual se trata "de una

el Rol No 2020-11, requerimiento presentado por Julio Francisco Javier Fuenzalida Asmussen respecto de las mismas normas. Rol No 1856-10 (2020-11)-INA. Sentencia de fecha 2 de mayo de 2012. Voto por acoger el requerimiento, considerando $10^{\circ}$. "Que, en consecuencia, debe tenerse presente que el contrato de salud, desde el punto de vista de este Tribunal, es un contrato de tracto sucesivo, de orden público y distinto a un contrato de seguro propio del derecho privado. Esta conceptualización, como se verá, es esencial en las razones del Tribunal para acoger el presente requerimiento". Tribunal Constitucional: Requerimiento de inaplicabilidad por inconstitucionalidad de Raúl Martínez Castillo respecto de los artículos 38 de la Ley No 18.933, vigente con anterioridad a la Ley $N^{\circ}$ 20.015, en la parte que alude a la tabla de factor etáreo, 38 ter de la misma Ley $N^{o} 18.933,2^{\circ}$ de la Ley $N^{o} 20.015$ y 199 del D.F.L. No 1, de 2005, del Ministerio de Salud, en los autos Rol No 20.756-2009 sustanciados ante el Tribunal Arbitral de la Superintendencia de Salud en contra de la Isapre Colmena Golden Cross S.A. Rol No 1572-09. Sentencia de fecha 30 de noviembre de 2010. Considerando $40^{\circ}$.

34 Tribunal Constitucional: Requerimiento de inaplicabilidad por inconstitucionalidad presentado por Sheila Hasbún Bernier respecto del inciso tercero del artículo 38 y artículo 38 bis de la Ley $N^{o} 18.933$, al que se acumuló el Rol No 2020-11, requerimiento presentado por Julio Francisco Javier Fuenzalida Asmussen respecto de las 
relación de derecho fundamental entre las partes"35. Incluso más, el voto por acoger el requerimiento de los jueces constitucionales, apoyándose en las enseñanzas de la Corte Suprema, identifica la naturaleza de las Isapres como "servicio público desarrollado por particulares cuyo giro es cubrir las acciones de salud contenidas en la Constitución Política de la República"36.

Por esta vía, el ordenamiento jurídico hace responsable directo del respeto, protección y garantía del derecho humano a disfrutar del más alto nivel posible de salud física y mental, además del Estado, a un particular. Este mismo rasgo distintivo que se hace presente en el contrato de salud puede encontrarse en el contrato de educación respecto del derecho a la educación; en el contrato de administración de pensiones respecto del derecho a la pensión; en el contrato de crédito hipotecario respecto del derecho a la vivienda y, lo que es aun más evidente, en el contrato de trabajo respecto del conjunto de derechos humanos involucrados en el trabajo.

mismas normas. Rol No 1856-10 (2020-11)-INA. Sentencia de fecha 2 de mayo de 2012. Voto por acoger el requerimiento, considerando $13^{\circ}$.

35 Tribunal Constitucional: Requerimiento de inaplicabilidad por inconstitucionalidad presentado por Sheila Hasbuin Bernier respecto del inciso tercero del artículo 38 y artículo 38 bis de la Ley No 18.933, al que se acumuló el Rol No 2020-11, requerimiento presentado por Julio Francisco Javier Fuenzalida Asmussen respecto de las mismas normas. Rol No 1856-10 (2020-11)-INA. Sentencia de fecha 2 de mayo de 2012. Voto por acoger el requerimiento, considerando $15^{\circ}$.

36 Tribunal Constitucional: Requerimiento de inaplicabilidad por inconstitucionalidad presentado por Sheila Hasbún Bernier respecto del inciso tercero del artículo 38 y artículo 38 bis de la Ley $N^{o} 18.933$, al que se acumuló el Rol No 2020-11, requerimiento presentado por Julio Francisco Javier Fuenzalida Asmussen respecto de las mismas normas. Rol No 1856-10 (2020-11)-INA. Sentencia de fecha 2 de mayo de 2012. Voto por acoger el requerimiento, considerando $11^{\circ}$. " [...] Tales progresivas regulaciones tienden a otorgar garantías al cotizante en el entendido que se trata de un servicio público desarrollado por particulares, como son las acciones de salud contenidas en la Constitución Política de la República, y que por lo mismo, en su establecimiento debe respetarse el conjunto de principios que emanan de la Ley Primera relacionados con la supremacía constitucional, su jerarquía superior, aplicación directa, interpretación conforme a ella e imposibilidad de invocar sus disposiciones para limitar las garantías que contempla, así como el efecto derogatorio de las normas pretéritas que están en contradicción con ella. En consecuencia, la interpretación de los pactos celebrados entre los cotizantes y las instituciones de salud previsional no puede regirse únicamente por los criterios que para ese fin dispone el derecho común, ya que no se trata de una relación nacida de una plena autonomía privada. Para tales efectos debe considerarse, también, la vigencia de las facultades de ejercicio que han sido otorgadas a las Isapres conforme al criterio evolutivo de la legislación que regula la actividad de dichas instituciones a la luz de los señalados principios y parámetros contenidos en la Carta Fundamental. Conforme a dichos criterios es que se ha asentado por esta Corte la doctrina uniforme que sostiene que la actualización de los planes de salud por aplicación de la tabla de factores contenidas en los contratos no importa una adecuación del mismo sino el ejercicio de una facultad de orden contractual, que el ordenamiento jurídico reconoce a las instituciones de salud". Corte Suprema: Sergio Carrasco Delgado contra Isapre Consalud S.A. Recurso de Protección. Rol No 8837-2010. Sentencia de fecha 28 de enero de 2011. Considerando $7^{\circ}$. 


\subsubsection{Elementos indisponibles del contrato por las partes}

El voto por acoger el requerimiento de inaplicabilidad por inconstitucionalidad destacó los elementos indisponibles por las partes, id est, hay elementos en los contratos que están fuera de la libertad de disposición de las partes.

El primero de estos elementos indisponibles para las partes en un contrato son obviamente los derechos humanos. Por cierto, el legítimo ejercicio de la autonomía de la voluntad no puede implicar privación o supresión del legítimo goce y ejercicio de un derecho humano. Así, en su jurisprudencia, el Tribunal Constitucional ha reiterado que "La existencia de un contrato no es impedimento para que se respeten y promuevan los derechos de las personas. Sostener lo contrario implicaría la posibilidad de que invocando la autonomía de la voluntad dichos derechos pudieran ser menoscabados o lesionados en su esencia" 37 . Asimismo, por supuesto que el "contrato no puede implicar una modulación flagrante de derechos". En concepto de los jueces constitucionales las facultades de disponer de las cláusulas de un contrato por las partes deben estar reguladas y limitadas de tal manera que "el derecho fundamental se vuelva realizable y ejercitable". De este modo, desde hace tiempo, la jurisprudencia de la Corte Europea de Derechos Humanos ha asentado el principio de que los instrumentos de derechos humanos tienen por objeto garantizar derechos prácticos y efectivos y no derechos que sean teóricos o ilusorios ${ }^{38}$. En esta línea, los jueces constitucionales concretamente señalan que "las normas que rigen el contrato de prestación de servicios de salud previsional no pueden permitir la actuación arbitraria y afectación desproporcionada de derechos", en nuestra opinión, porque en último término tornaría los derechos involucrados en teóricos o ilusorios ${ }^{39}$.

37 Tribunal Constitucional: Requerimiento de inaplicabilidad por inconstitucionalidad presentado por Sheila Hasbún Bernier respecto del inciso tercero del artículo 38 y artículo 38 bis de la Ley No 18.933, al que se acumuló el Rol No 2020-11, requerimiento presentado por Julio Francisco Javier Fuenzalida Asmussen respecto de las mismas normas. Rol No 1856-10 (2020-11)-INA. Sentencia de fecha 2 de mayo de 2012. Voto por acoger el requerimiento, considerando $13^{\circ}$. Vid. STC Rol No 976, considerandos $40^{\circ}, 41^{\circ}$ y $43^{\circ}$; Rol No 1218 , motivos $41^{\circ}$ y $55^{\circ}$; Rol No 1287 , considerandos $35^{\circ}, 41^{\circ}$ y $60^{\circ}$.

38 "The Convention is intended to guarantee not rights that are theoretical or illusory but rights that are practical and effective". Airey v. Ireland, judgment of 9 October 1979 (Application № 6289/73), Series A no. 32, p. 9, para. 24; Vid. "Belgian Linguistic" case, Series A no. 6, judgment of 23 July 1968, p. 31, paras. 3 in fine and 4; Golder case, judgment of 21 February 1975 (Series A no. 18), p. 18, para. 35 in fine; Luedicke, Belkacem and Koç case, judgment of 28 November 1978, Series A no. 29, pp. 17-18; para. 42; Marckx case, judgment of 13 June 1979, Series A No 31, p. 15, para. 31; García Manibardo v. Spain, Application No 38695/97, para. 43.

39 Tribunal Constitucional: Requerimiento de inaplicabilidad por inconstitucionalidad presentado por Sheila Hasbuin Bernier respecto del inciso tercero del artículo 38 y artículo 38 bis de la Ley No 18.933, al que se acumuló el Rol No 2020-11, requerimiento presentado por Julio Francisco Javier Fuenzalida Asmussen respecto de las 
Específicamente, el voto por acoger el requerimiento se refiere al derecho a la igualdad y a la prohibición de la discriminación. En este sentido, los jueces constitucionales señalan que "[1]a igualdad ante la ley no es un bien disponible y modulado por los efectos de un contrato entre la Isapre y el cotizante" 40 .

\subsubsection{Principio de igualdad y libertad contractual}

Ya hemos indicado que en el contrato de salud no hay igualdad de poder negociador y de conclusión de contratos entre la Isapre y el cotizante particular. En este tipo de relaciones contractuales entre "un servicio público desarrollado por particulares y los propios cotizantes adscritos a la Isapre (sic) el punto de partida en el juicio de igualdad no es precisamente el de un poder equivalente" 41 . En efecto, en el contrato de salud hay un contratante fuerte (la Isapre) y un contratante débil (el cotizante), y ambos se encuentran en una situación real de desigualdad, que le corresponde al legislador corregir y en último término a los derechos humanos quienes van en auxilio del contratante débil para protegerlo y así restablecer el equilibrio original inexistente. De este modo, los jueces constitucionales han afirmado que "[s]i no hay tal regulación real, ese margen de libertad, a favor del contratante fuerte, es todo el espacio del abuso del derecho" ${ }^{2}$. Consecuentemen-

mismas normas. Rol No 1856-10 (2020-11)-INA. Sentencia de fecha 2 de mayo de 2012. Voto por acoger el requerimiento, considerando 33º Tribunal Constitucional: Proceso iniciado de oficio para decidir sobre la constitucionalidad del artículo 38 ter de la Ley de Isapres y cuya sentencia se publicó en el Diario Oficial el 9 de agosto de 2010. Rol No 1710-10. Sentencia de fecha 6 de agosto de 2010. Considerandos $145^{\circ}$ y $155^{\circ}$. "It would be illusory if a Contracting State's domestic legal system allowed an individual to bring a civil action before a court without ensuring that the case would be determined by a final decision in the judicial proceedings. It would be inconceivable for Article $6 \$ 1$ to describe in detail procedural guarantees afforded to litigants -proceedings that are fair, public and expeditious- without guaranteeing the parties that their civil disputes will be finally determined". Case of Kutic v. Croatia. (Application No 48778/99) Judgment of 1 March 2002, para. 25.

40 Tribunal Constitucional: Requerimiento de inaplicabilidad por inconstitucionalidad presentado por Sheila Hasbuin Bernier respecto del inciso tercero del artículo 38 y artículo 38 bis de la Ley No 18.933, al que se acumuló el Rol No 2020-11, requerimiento presentado por Julio Francisco Javier Fuenzalida Asmussen respecto de las mismas normas. Rol No 1856-10 (2020-11)-INA. Sentencia de fecha 2 de mayo de 2012. Voto por acoger el requerimiento, considerando $13^{\circ}$.

41 Tribunal Constitucional: Requerimiento de inaplicabilidad por inconstitucionalidad presentado por Sheila Hasbuin Bernier respecto del inciso tercero del artículo 38 y artículo 38 bis de la Ley $N^{o} 18.933$, al que se acumuló el Rol No 2020-11, requerimiento presentado por Julio Francisco Javier Fuenzalida Asmussen respecto de las mismas normas. Rol No 1856-10 (2020-11)-INA. Sentencia de fecha 2 de mayo de 2012. Voto por acoger el requerimiento, considerando $13^{\circ}$.

42 Tribunal Constitucional: Requerimiento de inaplicabilidad por inconstitucionalidad presentado por Sheila Hasbuin Bernier respecto del inciso tercero del artículo 38 y artículo 38 bis de la Ley No 18.933, al que se acumuló 
te, se ha afirmado que por las posibilidades que franquea la ley, "El principio de igualdad queda vulnerado por este mandato de modificación unilateral del contrato de salud, por parte de la Isapre" 43 .

El estándar que han fijado los jueces constitucionales en cuanto al poder de las partes en un contrato, en este caso, en el contrato de salud, es el siguiente: "De lo que se trata es que se mantenga un cierto equilibrio entre las partes del mismo. Este es el mandato que el legislador debe cumplir, cuando se le obliga a que garantice la ejecución de las acciones de salud (artículo $19 N^{\circ} 9^{\circ}$ de la Constitución). El derecho a la protección de la salud se desvirtúa si una de las partes del contrato tiene cero o ningún poder negociador. Y en el contrato de salud, la Isapre fija las condiciones, revisa el contrato anualmente y tiene garantías respecto del pago de la cotización" 44 .

Desde el punto de vista de la articulación entre el principio de libertad contractual y el principio de igualdad, se proponen dos etapas, al menos, en las que se debería realizar esta articulación. En la etapa de inicio y ejecución de la relación contractual, o el punto de partida, y en la etapa de los resultados del acto o relación contractual, o punto de llegada. Como punto de partida o de igualdad de negociación, se debe reglar la relación entre Isapre y cotizante en el marco del principio de igualdad y del respeto de otros derechos fundamentales ${ }^{45}$. Como

el Rol No 2020-11, requerimiento presentado por Julio Francisco Javier Fuenzalida Asmussen respecto de las mismas normas. Rol No 1856-10 (2020-11)-INA. Sentencia de fecha 2 de mayo de 2012. Voto por acoger el requerimiento, considerando $14^{\circ}$.

43 Tribunal Constitucional: Requerimiento de inaplicabilidad por inconstitucionalidad presentado por Sheila Hasbuin Bernier respecto del inciso tercero del artículo 38 y artículo 38 bis de la Ley $N^{o} 18.933$, al que se acumuló el Rol No 2020-11, requerimiento presentado por Julio Francisco Javier Fuenzalida Asmussen respecto de las mismas normas. Rol No 1856-10 (2020-11)-INA. Sentencia de fecha 2 de mayo de 2012. Voto por acoger el requerimiento, considerando $15^{\circ}$.

44 Tribunal Constitucional: Requerimiento de inaplicabilidad por inconstitucionalidad presentado por Sheila Hasbún Bernier respecto del inciso tercero del artículo 38 y artículo 38 bis de la Ley No 18.933, al que se acumuló el Rol No 2020-11, requerimiento presentado por Julio Francisco Javier Fuenzalida Asmussen respecto de las mismas normas. Rol No 1856-10 (2020-11)-INA. Sentencia de fecha 2 de mayo de 2012. Voto por acoger el requerimiento, considerando $15^{\circ}$. Tribunal Constitucional: Requerimiento de inaplicabilidad por inconstitucionalidad de Raúl Martínez Castillo respecto de los artículos 38 de la Ley No 18.933, vigente con anterioridad a la Ley No 20.015, en la parte que alude a la tabla de factor etáreo, 38 ter de la misma Ley $N^{o} 18.933,2^{\circ}$ de la Ley $N^{o} 20.015$ y 199 del D.F.L. No 1, de 2005, del Ministerio de Salud, en los autos Rol No 20.756-2009, sustanciados ante el Tribunal Arbitral de la Superintendencia de Salud en contra de la Isapre Colmena Golden Cross S.A. Rol No 1572-09. Sentencia de fecha 30 de noviembre de 2010. Considerando 61 ${ }^{\circ}$.

45 Tribunal Constitucional: Requerimiento de inaplicabilidad por inconstitucionalidad presentado por Sheila Hasbún Bernier respecto del inciso tercero del artículo 38 y artículo 38 bis de la Ley $N^{\circ} 18.933$, al que se acumuló el Rol No 2020-11, requerimiento presentado por Julio Francisco Javier Fuenzalida Asmussen respecto de las 
punto de llegada o de igualdad de resultados, el poder del cotizante debería crecer para negociar alteraciones o modificaciones a la relación contractual en términos más justos. Y, esto último, dicho por los propios jueces constitucionales, aunque muchas veces, hablar de 'justicia' o de 'equidad' en un análisis jurídico parece una herejía. En definitiva, de lo que se trata es "simplemente de reducir la abismante diferencia de poder correlativo en la fijación de los términos contractuales del plan de salud" 46 .

En el contexto del principio de igualdad, el voto por acoger el requerimiento llega a la conclusión que los preceptos de ley escrutados violan "el último límite de la igualdad ante la ley que es la ausencia de razonabilidad y proporcionalidad en la determinación del precio base". En efecto, no se cumple con el criterio de la razonabilidad de la medida si la ley permite que una de las partes del contrato tenga cero o ningún poder negociador, sobre todo en casos como del contrato de salud, en que la ausencia total de poder negociador afecta el derecho fundamental a la protección de la salud. Así, la facultad de revisión y modificación anual en forma unilateral del contrato de salud por parte de la Isapre carece de razonabilidad. Tampoco es razonable reconocerle al cotizante un poder básico o elemental de negociación que sólo permita renunciar a derechos fundamentales tales como el derecho a la protección de la salud, ya sea porque admite reducción de prestaciones o bien porque se ve forzado económicamente a cambiar de institución de salud previsional ${ }^{47}$. En este contexto, por tanto, el voto por acoger el requerimiento afirma que "las reglas establecidas en la ley sobre el reajuste del precio base, sometidas a un análisis de racionalidad, no cumplen con los requisitos de idoneidad, pertinencia ni proporcionalidad" 48 .

\footnotetext{
mismas normas. Rol No 1856-10 (2020-11)-INA. Sentencia de fecha 2 de mayo de 2012. Voto por acoger el requerimiento, considerando $12^{\circ}$.

46 Tribunal Constitucional: Requerimiento de inaplicabilidad por inconstitucionalidad presentado por Sheila Hasbuin Bernier respecto del inciso tercero del artículo 38 y artículo 38 bis de la Ley No 18.933, al que se acumuló el Rol No 2020-11, requerimiento presentado por Julio Francisco Javier Fuenzalida Asmussen respecto de las mismas normas. Rol No 1856-10 (2020-11)-INA. Sentencia de fecha 2 de mayo de 2012. Voto por acoger el requerimiento, considerando $12^{\circ}$.

47 Tribunal Constitucional: Requerimiento de inaplicabilidad por inconstitucionalidad presentado por Sheila Hasbuin Bernier respecto del inciso tercero del artículo 38 y artículo 38 bis de la Ley $N^{o} 18.933$, al que se acumuló el Rol No 2020-11, requerimiento presentado por Julio Francisco Javier Fuenzalida Asmussen respecto de las mismas normas. Rol No 1856-10 (2020-11)-INA. Sentencia de fecha 2 de mayo de 2012. Voto por acoger el requerimiento, considerando $15^{\circ}$.

48 Tribunal Constitucional: Requerimiento de inaplicabilidad por inconstitucionalidad presentado por Sheila Hasbún Bernier respecto del inciso tercero del artículo 38 y artículo 38 bis de la Ley No 18.933, al que se acumuló
} 
Por otro lado, no se cumple con el criterio de la proporcionalidad de la medida si la determinación primera, única y definitiva del precio de un plan de salud está casi siempre en las manos discrecionales de la Isapre y la ley no establece formas de impedir estas alzas carentes de justificación en un baremo objetivo. Así, se ha afirmado que "para resguardar la proporcionalidad en las alzas que afectarán los derechos de los afiliados, el legislador debe señalar los extremos de tal modificación" ${ }^{49}$. Por esta razón, los jueces constitucionales han afirmado que "la ejecución del contrato en un permanente proceso de desigualdad de poder, información, pruebas y unilateralismo modificatorio, nos lleva a concluir que los preceptos legales impugnados vulneran el último límite de la igualdad ante la ley que es la ausencia de razonabilidad y proporcionalidad en la determinación del precio base" 50 . En esta línea, los jueces constitucionales han seguido las enseñanzas y razonamientos proporcionados por la Corte Suprema, en una fructífera y regocijante comunicabilidad horizontal de las argumentaciones constitucionales. Así, el Tribunal Constitucional ha dicho que la Corte Suprema "ha reprochado a las Isapres que "afirmar con cifras y criterios generales que los costos de la institución recurrida para otorgar las prestaciones a que está obligada han aumentado, sin que ello se demuestre o justifique de manera cabal, pormenorizada y racional, por lo que no puede pretenderse reajustar los precios con los solos antecedentes que se invocan por quien está obligado a brindar por contrato que reviste características de orden público y jerarquía constitucional las prestaciones de un bien como la salud's1.

el Rol No 2020-11, requerimiento presentado por Julio Francisco Javier Fuenzalida Asmussen respecto de las mismas normas. Rol No 1856-10 (2020-11)-INA. Sentencia de fecha 2 de mayo de 2012. Voto por acoger el requerimiento, considerando $43^{\circ}$.

49 Tribunal Constitucional: Requerimiento de inaplicabilidad por inconstitucionalidad presentado por Sheila Hasbun Bernier respecto del inciso tercero del artículo 38 y artículo 38 bis de la Ley $N^{\circ}$ 18.933, al que se acumuló el Rol No 2020-11, requerimiento presentado por Julio Francisco Javier Fuenzalida Asmussen respecto de las mismas normas. Rol No 1856-10 (2020-11)-INA. Sentencia de fecha 2 de mayo de 2012. Voto por acoger el requerimiento, considerando $8^{\circ}$.

50 Tribunal Constitucional: Requerimiento de inaplicabilidad por inconstitucionalidad presentado por Sheila Hasbuin Bernier respecto del inciso tercero del artículo 38 y artículo 38 bis de la Ley $N^{o} 18.933$, al que se acumuló el Rol No 2020-11, requerimiento presentado por Julio Francisco Javier Fuenzalida Asmussen respecto de las mismas normas. Rol No 1856-10 (2020-11)-INA. Sentencia de fecha 2 de mayo de 2012. Voto por acoger el requerimiento, considerando $26^{\circ}$.

51 Tribunal Constitucional: Requerimiento de inaplicabilidad por inconstitucionalidad presentado por Sheila Hasbuin Bernier respecto del inciso tercero del artículo 38 y artículo 38 bis de la Ley $N^{o} 18.933$, al que se acumuló el Rol No 2020-11, requerimiento presentado por Julio Francisco Javier Fuenzalida Asmussen respecto de las mismas normas. Rol No 1856-10 (2020-11)-INA. Sentencia de fecha 2 de mayo de 2012. Voto por acoger el requerimiento, considerando $41^{\circ}$. "Que en la carta a que se ha hecho referencia y con el cual la recurrida 
En definitiva, la ley no satisface el estándar de la proporcionalidad, ya que permite a la Isapre reajustar unilateralmente el precio base sin justificación alguna y de esta manera establecer "un precio que no guarda relación alguna con las rentas de los afiliados" 52 .

Por último, los jueces constitucionales plantean el criterio de los principios generales de derecho. En efecto, el análisis de los preceptos legales impugnados no resistiría tampoco el escrutinio a la luz de los principios generales de derecho. En este sentido, se afirma que "puede considerarse como un principio general de derecho el que las modificaciones de los contratos sólo pueden tener lugar por la voluntad conteste de las partes por ellos vinculadas, toda vez que, por definición, el contrato es un acuerdo de voluntades que obliga en virtud de la intención libre y conscientemente expresada en tal sentido por los sujetos de derecho que lo celebran" ${ }^{3}$. Así, los jueces constitucionales afirman el principio general en el

pretende justificar su decisión de adecuar el plan de salud del recurrente no satisface a juicio de esta Corte la exigencia de razonabilidad referida en el motivo anterior. En efecto, ésta se circunscribe a afirmar con cifras y criterios generales que los costos de la institución recurrida para otorgar las prestaciones a que está obligada han aumentado, sin que ello se demuestre o justifique de manera cabal, pormenorizada y racional, por lo que no puede pretenderse reajustar los precios con los solos antecedentes que se invocan por quien está obligado a brindar por contrato que reviste características de orden público y jerarquía constitucional las prestaciones de un bien como la salud". Corte Suprema: Calderón Rivero, Patricia Mercedes contra Colmena Golden Cross S.A. Recurso de Protección. Rol No 192-2011. Sentencia de fecha 28 de enero de 2011. Considerando $4^{\circ}$. "Que la interpretación y aplicación restrictiva de las circunstancias que justifican una revisión objetiva se apoya en el carácter extraordinario de la facultad de la Isapre y la particular situación en que se encuentran los afiliados a un plan frente a la nombrada institución a la hora de decidir si se mantienen o no las condiciones de contratación. De este modo se salvaguardan, por una parte, los legítimos intereses económicos de las instituciones frente a las variaciones de sus costos operativos y, por otra, se protege la situación de los afiliados, en la medida que la revisión de los precios sólo resultará legítima por una alteración objetiva y esencial de las prestaciones, apta para afectar a todo un sector de afiliados o, a lo menos, a todos los que contrataron un mismo plan. Lo anterior sin perjuicio de que, en su caso y libremente, se puedan pactar modificaciones de las condiciones particulares si todos los interesados convienen en ello". Corte Suprema: Pino Acosta, Cristián contra Colmena Golden Cross S.A. Recurso de Protección. Rol No 601-2011. Sentencia de fecha 28 de enero de 2011. Considerando $5^{\circ}$.

52 Tribunal Constitucional: Requerimiento de inaplicabilidad por inconstitucionalidad presentado por Sheila Hasbuin Bernier respecto del inciso tercero del artículo 38 y artículo 38 bis de la Ley $N^{o} 18.933$, al que se acumuló el Rol No 2020-11, requerimiento presentado por Julio Francisco Javier Fuenzalida Asmussen respecto de las mismas normas. Rol No 1856-10 (2020-11)-INA. Sentencia de fecha 2 de mayo de 2012. Voto por acoger el requerimiento, considerando $44^{\circ}$.

53 Tribunal Constitucional: Requerimiento de inaplicabilidad por inconstitucionalidad presentado por Sheila Hasbuin Bernier respecto del inciso tercero del artículo 38 y artículo 38 bis de la Ley $N^{o} 18.933$, al que se acumuló el Rol No 2020-11, requerimiento presentado por Julio Francisco Javier Fuenzalida Asmussen respecto de las mismas normas. Rol No 1856-10 (2020-11)-INA. Sentencia de fecha 2 de mayo de 2012. Voto por acoger el requerimiento, considerando $16^{\circ}$. 
derecho de los contratos de que "el consentimiento es esencial en la contratación y en sus etapas sucesivas de modificación" 54 . Consecuentemente, la facultad de la Isapre para reajustar anualmente unilateralmente los precios base de los contratos de salud previsional sin que la ley fije los límites o máximos de alza atenta en contra del principio del consentimiento libre, afectando el goce de derechos humanos básicos, en una relación jurídica primordialmente de derecho fundamental. En efecto, el voto por acoger el requerimiento señala que "las normas impugnadas en autos, al conceder libertad discrecional a las Isapres para reajustar anualmente los precios bases de los contratos de salud previsional, entrañan una normativa exorbitante a los principios generales de los contratos, especialmente a los contratos de salud reconocidos en el artículo 19 No 9 de la Constitución, que no tiene justificación racional alguna y configura un tratamiento de privilegio a favor de tales instituciones" 55 .

Por otra parte, como se ha dicho, la ley, al conceder libertad discrecional a las Isapres para reajustar anualmente los precios base de los contratos de salud previsional "vulnera la garantía constitucional de igualdad en el trato que la ley debe dispensar a los imperados por ella, según lo mandata el numeral $2^{\circ}$ del artículo 19 constitucional" 56 .

Adicionalmente, si bien el contrato de salud implica una relación contractual bajo la forma de un contrato de seguro, su objeto y fin no es garantizar a todo evento y a cualquier precio la expectativa de rentabilidad de los aseguradores -cueste lo que cueste-, porque el fin de este contrato es garantizar el efectivo acceso de las personas a la protección de la salud y la seguridad social, bienes todos que son

54 Tribunal Constitucional: Requerimiento de inaplicabilidad por inconstitucionalidad presentado por Sheila Hasbún Bernier respecto del inciso tercero del artículo 38 y artículo 38 bis de la Ley No 18.933, al que se acumuló el Rol No 2020-11, requerimiento presentado por Julio Francisco Javier Fuenzalida Asmussen respecto de las mismas normas. Rol No 1856-10 (2020-11)-INA. Sentencia de fecha 2 de mayo de 2012. Voto por acoger el requerimiento, considerando $17^{\circ}$.

55 Tribunal Constitucional: Requerimiento de inaplicabilidad por inconstitucionalidad presentado por Sheila Hasbún Bernier respecto del inciso tercero del artículo 38 y artículo 38 bis de la Ley No 18.933, al que se acumuló el Rol No 2020-11, requerimiento presentado por Julio Francisco Javier Fuenzalida Asmussen respecto de las mismas normas. Rol No 1856-10 (2020-11)-INA. Sentencia de fecha 2 de mayo de 2012. Voto por acoger el requerimiento, considerando $18^{\circ}$.

56 Tribunal Constitucional: Requerimiento de inaplicabilidad por inconstitucionalidad presentado por Sheila Hasbún Bernier respecto del inciso tercero del artículo 38 y artículo 38 bis de la Ley $N^{o} 18.933$, al que se acumuló el Rol No 2020-11, requerimiento presentado por Julio Francisco Javier Fuenzalida Asmussen respecto de las mismas normas. Rol No 1856-10 (2020-11)-INA. Sentencia de fecha 2 de mayo de 2012. Voto por acoger el requerimiento, considerando $18^{\circ}$. 
imprescindibles para los individuos y que se encuentran amparados por derechos fundamentales, lo que restringe y modula correspondientemente las facultades del contratante fuerte. De esta manera, la facultad superlativa unilateral de las Isapres para reajustar periódicamente los precios base de los contratos de salud previsional que celebran con sus afiliados merece por esta vía también un reproche de constitucionalidad 57 .

\subsubsection{La ineludible función social que tienen los contratos de salud}

El voto por acoger el requerimiento se refiere a la función social de los contratos de salud. Constitucionalmente hablando, esta expresión es bien conocida, tanto en nuestro Derecho como en el Derecho comparado. En nuestro orden jurídico, la Constitución chilena consagra la conocida función social de la propiedad en el artículo 19 No 24. En el caso de marras, los jueces constitucionales se refieren a la función social de los contratos de salud, sobre todo teniendo en cuenta que el objeto de los contratos mencionados es la provisión de un servicio vital del que no pueden prescindir quienes los celebran; su finalidad es garantizar el acceso efectivo de las personas a la protección de su salud y a la seguridad social ${ }^{58}$. En este sentido, aquello que es constitucionalmente primordial es que estas relaciones contractuales permitan satisfacer derechos humanos, especialmente el derecho a la protección de la salud y el derecho a la seguridad social. Aquello que es central en el análisis es que los bienes que se encuentran en el corazón de estos contratos corresponden a bienes constitucionalmente protegidos y que se identifican con "necesidades impostergables de las personas" y con "un servicio vital del que no pueden prescindir" 59 .

\footnotetext{
57 Tribunal Constitucional: Requerimiento de inaplicabilidad por inconstitucionalidad presentado por Sheila Hasbuin Bernier respecto del inciso tercero del artículo 38 y artículo 38 bis de la Ley $N^{\circ} 18.933$, al que se acumuló el Rol No 2020-11, requerimiento presentado por Julio Francisco Javier Fuenzalida Asmussen respecto de las mismas normas. Rol No 1856-10 (2020-11)-INA. Sentencia de fecha 2 de mayo de 2012. Voto por acoger el requerimiento, considerando $24^{\circ}$.

58 Tribunal Constitucional: Requerimiento de inaplicabilidad por inconstitucionalidad presentado por Sheila Hasbún Bernier respecto del inciso tercero del artículo 38 y artículo 38 bis de la Ley $N^{o} 18.933$, al que se acumuló el Rol No 2020-11, requerimiento presentado por Julio Francisco Javier Fuenzalida Asmussen respecto de las mismas normas. Rol No 1856-10 (2020-11)-INA. Sentencia de fecha 2 de mayo de 2012. Voto por acoger el requerimiento, considerando $24^{\circ}$.

59 Tribunal Constitucional: Requerimiento de inaplicabilidad por inconstitucionalidad presentado por Sheila Hasbuin Bernier respecto del inciso tercero del artículo 38 y artículo 38 bis de la Ley $N^{o} 18.933$, al que se acumuló el Rol No 2020-11, requerimiento presentado por Julio Francisco Javier Fuenzalida Asmussen respecto de las
} 
Estas necesidades básicas de todo ser humano y, por tanto, bienes públicos constitucionalmente protegidos, en virtud de lo dispuesto en los artículos $1^{\circ}, 4^{\circ}$, $5^{\circ}, 6^{\circ}, 7^{\circ}$ y 19 de la Constitución chilena, le otorgan el carácter de ineludible a la función social de los contratos de salud. Este mismo razonamiento que se aplica a los contratos de salud previsional se puede predicar respecto de los contratos en el ámbito de la educación, en el ámbito de la alimentación o en el ámbito de la vivienda.

En esta línea, los jueces constitucionales han señalado que "la ineludible función social que tienen los contratos de salud previsional, en el sentido de dar cobertura a necesidades impostergables de las personas, es incompatible con otorgar discrecionalidad a las entidades privadas que administran ese seguro para que reajusten los precios unilateralmente, sin importar si con ello restringen o limitan el acceso efectivo de sus afiliados al aseguramiento de salud. [...] Tal y como afirma la consolidada doctrina de este Tribunal sobre los contratos de salud previsional, es incuestionable la vigencia a su respecto de los derechos constitucionales de protección de la salud y a la seguridad social y, por tanto, las leyes que los regulan deben respetar el contenido esencial de tales derechos, de manera de impedir que la fijación de precios y las condiciones de acceso a las prestaciones aseguradas los vulneren" 60 .

\section{3. ¿Constitucionalización del Derecho civil o humanización del Derecho privado?}

En esta sentencia, el voto por acoger el requerimiento se refiere al fenómeno jurídico de la constitucionalización del Derecho civil. Junto con admitir y coincidir con el voto por acoger el recurso en lo relativo a este fenómeno jurídico, quizá vale la pena vincularlo con un fenómeno mucho más amplio. La constitucionalización del Derecho civil es una expresión de un fenómeno que se produce respecto de todo el ordenamiento, así, se puede hablar de la constitucionalización del Derecho

\footnotetext{
mismas normas. Rol No 1856-10 (2020-11)-INA. Sentencia de fecha 2 de mayo de 2012. Voto por acoger el requerimiento, considerando $24^{\circ}$.

60 Tribunal Constitucional: Requerimiento de inaplicabilidad por inconstitucionalidad presentado por Sheila Hasbuin Bernier respecto del inciso tercero del artículo 38 y artículo 38 bis de la Ley No 18.933, al que se acumuló el Rol No 2020-11, requerimiento presentado por Julio Francisco Javier Fuenzalida Asmussen respecto de las mismas normas. Rol No 1856-10 (2020-11)-INA. Sentencia de fecha 2 de mayo de 2012. Voto por acoger el requerimiento, considerando $34^{\circ}$. Vid. STC Rol No 1218 , considerandos $35^{\circ}, 37^{\circ}, 38^{\circ}, 39^{\circ}$ y $43^{\circ}$; Rol No 1287 , considerandos $35^{\circ}, 37^{\circ}, 38^{\circ}, 39^{\circ}$ y $43^{\circ}$; Rol No 1273 , considerando $79^{\circ}$, y Rol № 1710 , considerando $154^{\circ}$.
} 
penal, del Derecho laboral, del Derecho comercial, del Derecho administrativo, en fin, de todo aquel acto normativo que es el resultado de los medios estatales de producción del Derecho. Incluso, se podría hablar de la constitucionalización del Derecho internacional, pero esa es otra historia, porque en ese caso estaríamos hablando de un proceso de constitucionalización que se produciría allende las fronteras del Estado.

Sin embargo, este reconocimiento de un proceso de constitucionalización del orden jurídico interno, sobre todo de aquel orden que está destinado a regir las relaciones entre particulares, es sólo un aspecto acotado de esta evolución del Derecho. Para completar el fenómeno jurídico actual, habría que mencionar un proceso de real relevancia incluso a nivel global y que a su vez califica y distingue todos los procesos de constitucionalización -en la esfera interna e internacional-. Nos referimos a la puesta en el centro de las preocupaciones constitucionales o fundantes de una comunidad, al ser humano y su dignidad. La protección de la integralidad del ser humano y de sus derechos ha pasado a ser el rasgo característico y principalísimo de todo proceso de constitucionalización del Derecho. Este proceso se produce, entre otras razones, porque los derechos humanos se erigen como el reflejo normativo de valores y principios fundantes de una comunidad jurídica, id est, como un orden objetivo de valores reconocido y recogido en la normativa constitucional. Este orden objetivo de valores, recogido en la Constitución, se proyecta como un haz de luz, que cubre e ilumina todo el ordenamiento estatal, tanto en la esfera pública como en la del Derecho privado. Así se vislumbra claramente cómo se perfilan las normas con carácter constitucional -tales como los derechos humanos- como un parámetro de control, a través del principio de la interpretación conforme.

En este sentido, habría que despojar a este fenómeno de constitucionalización del Derecho (civil en este caso) de su connotación meramente formal en el sentido de sujeción de la norma infraconstitucional al instrumento constitucional y entenderlo como un proceso de humanización -en el sentido de los derechos humanos- del Derecho (civil en este caso). En efecto, se trata de la penetración de la perspectiva de los derechos humanos - de sus valores, principios y normas- en todo el Derecho o en todo el orden jurídico interno. Nuestra propuesta consistiría en que éste sería el verdadero rasgo característico del Derecho del siglo XXI. Y, al parecer, el voto por acoger el requerimiento, aun cuando no lo dice explícitamente, desarrollaría su argumentación en esta línea de reflexión.

En efecto, el voto por acoger el requerimiento señala que "la situación descrita es una manifestación concreta de un doble fenómeno jurídico de constitucionali- 
zación del Derecho Civil y de eficacia entre particulares de los derechos fundamentales. En cuanto al primer fenómeno, en relación con el postulado constitucional de 'igualdad en la ley', ciertas instituciones nodales de esa rama del Derecho y sus nociones fundantes han pasado a tener tutela constitucional, como es aquí el caso de la inmodificabilidad unilateral de los contratos por la sola voluntad de una de sus partes. Y, en cuanto a la eficacia entre particulares de los derechos fundamentales, todos ellos están vinculados al cumplimiento de los mandatos constitucionales (artículo $6^{\circ}$, inciso segundo, de la Constitución), impidiéndose la renuncia de derechos fundamentales regulados por la Constitución"61.

\section{Efecto horizontal de los derechos humanos}

El voto por acoger el requerimiento se refiere al fenómeno de la eficacia entre particulares de los derechos fundamentales. En este sentido, señalan que todos los particulares "están vinculados al cumplimiento de los mandatos constitucionales (artículo $6^{\circ}$, inciso segundo, de la Constitución), impidiéndose la renuncia de derechos fundamentales regulados por la Constitución"62.

En efecto, en este caso nos encontramos a una relación jurídica-privada, entre particulares, a la sazón la Isapre, por una parte, y el cotizante, por otra, y que se concreta en un contrato de salud previsional. Esta relación jurídico-privada se encuentra regulada por la ley especial, y en lo general, se aplican las normas generales de Derecho privado. Por tanto, los principios generales aplicables a este tipo de relaciones son aquellos propios del Derecho de los contratos, tales como el de la autonomía de la voluntad, el de la libertad contractual y el del libre consentimiento. En este contexto, el fenómeno de la eficacia entre particulares de los derechos fundamentales implica que los privados, en sus relaciones jurídicas, se encuentran evidentemente sujetos a los derechos humanos, debiendo respetarlos y protegerlos ${ }^{63}$.

61 Tribunal Constitucional: Requerimiento de inaplicabilidad por inconstitucionalidad presentado por Sheila Hasbuin Bernier respecto del inciso tercero del artículo 38 y artículo 38 bis de la Ley No 18.933, al que se acumuló el Rol No 2020-11, requerimiento presentado por Julio Francisco Javier Fuenzalida Asmussen respecto de las mismas normas. Rol No 1856-10 (2020-11)-INA. Sentencia de fecha 2 de mayo de 2012. Voto por acoger el requerimiento, considerando $19^{\circ}$.

62 Tribunal Constitucional: Requerimiento de inaplicabilidad por inconstitucionalidad presentado por Sheila Hasbuin Bernier respecto del inciso tercero del artículo 38 y artículo 38 bis de la Ley $N^{o} 18.933$, al que se acumuló el Rol No 2020-11, requerimiento presentado por Julio Francisco Javier Fuenzalida Asmussen respecto de las mismas normas. Rol No 1856-10 (2020-11)-INA. Sentencia de fecha 2 de mayo de 2012. Voto por acoger el requerimiento, considerando $19^{\circ}$.

63 Aguilar Cavallo, Gonzalo: "La responsabilidad por vulneración de derechos fundamentales y el reconocimiento del principio de supremacía de dichos derechos: Comentario de la sentencia del Tribunal 
En el caso del contrato de salud previsional, se trata de una relación jurídica entre privados, pero con una dimensión particular, evidenciada en el objeto y fin del contrato, el cual es proveer un bien vital para una necesidad imprescindible de todo ser humano y garantizar el acceso afectivo de las personas a la protección de la salud y de la seguridad social. Esta dimensión particular del contrato de salud es en realidad una dimensión objetiva de los derechos humanos, los cuales actúan como parámetro de control e interpretación del mismo contrato. A través del contrato de salud -una relación jurídico-privada-se satisfacen (o no!) derechos fundamentales, en este caso, el derecho a la protección de la salud y el derecho a la seguridad social. En el contrato de salud, la eficacia entre particulares se observa en que el actuar unilateral y discrecional de la Isapre puede culminar en una vulneración directa de derechos fundamentales, a saber: el derecho a la igualdad, el derecho a la protección de la salud y la seguridad social. Pero, al mismo tiempo, más ampliamente, la eficacia entre particulares de los derechos fundamentales puede adquirir una dimensión indirecta, en el sentido de que la Isapre no vulnera directamente con su actuar derechos fundamentales, pero sometido el contrato a una interpretación por el juez, el acto contractual debería entenderse en el sentido de que sus cláusulas no produzcan o conduzcan a ninguna violación de derechos humanos, tales como el derecho a la igualdad, el derecho a la protección de la salud y la seguridad social. La justificación de este efecto indirecto de la eficacia entre particulares de los derechos fundamentales reside en que los derechos humanos irradian o expanden todos sus efectos a la globalidad del orden jurídico estatal y a la totalidad de las relaciones jurídicas, incluso entre privados.

La dimensión objetiva de los derechos humanos, se ha dicho, implica que estos derechos actúan como parámetro de control e interpretación del orden jurídico, razón por la cual el análisis de los preceptos legales impugnados se hace a la luz de dichos derechos. Los derechos fundamentales se erigen como un parámetro de control material, superlativo y especialmente potente. En el caso del contrato de salud, el legislador ha fallado en regular completamente el ejercicio de los derechos fundamentales involucrados, ya que no ha fijado los límites máximos para cada alza unilateral del contrato, dejándolo a la determinación discrecional de la Isapre, el contratante fuerte ${ }^{64}$. Así, "preceptos legales impugnados vulneran

Constitucional recaída en el artículo 2331 del Código Civil”, en Revista de Derecho de la Universidad Católica del Norte, Año 9, No 1 (2009), pp. 223-250; Aguilar Cavallo, Gonzalo y Contreras Rojas, Cristián: "El efecto horizontal de los derechos humanos y su reconocimiento expreso en las relaciones laborales en Chile", en Ius et Praxis, Vol. 13, No 1 (2007), pp. 205-243.

64 Tribunal Constitucional: Requerimiento de inaplicabilidad por inconstitucionalidad presentado por Sheila Hasbuin Bernier respecto del inciso tercero del artículo 38 y artículo 38 bis de la Ley No 18.933, al que se acumuló 
el último límite de la igualdad ante la ley que es la ausencia de razonabilidad y proporcionalidad en la determinación del precio base" 65 . De este modo, se vulnera el principio de reserva legal que entrega sólo al legislador la regulación, delimitación, configuración y limitación de los derechos fundamentales ${ }^{66}$. Así, "[e]sta vulneración de la reserva legal de un contrato sobre un derecho constitucional es flagrante y constituye la principal desprotección de un derecho como la igualdad ante la ley, que simplemente sólo en el contorno del contrato es legal pero su reajustabilidad es contractual, unilateral y no controlada" 67 .

La necesaria regulación legal de los derechos fundamentales y su exclusión de la autorregulación tan propia de las relaciones jurídico-privadas y del Derecho privado en general, encuentra su justificación en la esfera de lo indecidible y en la desproporcionada diferencia de poder entre los contratantes, cada vez más frecuente en el mundo jurídico-privado. Los jueces constitucionales recurren expresamente a las palabras del conocido profesor Ferrajoli, quien señala que "una autorregulación es inconcebible (...). Por eso, es a la esfera pública, a sus instituciones de gobierno y sobre todo a específicas instituciones de garantía, funcionalmente encargadas de la tutela de los intereses generales y de los derechos fundamentales de todos, a la que está necesariamente confiada la heterorregulación del mercado, a través de la imposición de límites y vínculos legales a los poderes empresariales"68.

el Rol No 2020-11, requerimiento presentado por Julio Francisco Javier Fuenzalida Asmussen respecto de las mismas normas. Rol No 1856-10 (2020-11)-INA. Sentencia de fecha 2 de mayo de 2012. Voto por acoger el requerimiento, considerandos $37^{\circ}$ y $38^{\circ}$.

65 Tribunal Constitucional: Requerimiento de inaplicabilidad por inconstitucionalidad presentado por Sheila Hasbin Bernier respecto del inciso tercero del artículo 38 y artículo 38 bis de la Ley No 18.933, al que se acumuló el Rol No 2020-11, requerimiento presentado por Julio Francisco Javier Fuenzalida Asmussen respecto de las mismas normas. Rol No 1856-10 (2020-11)-INA. Sentencia de fecha 2 de mayo de 2012. Voto por acoger el requerimiento, considerando $26^{\circ}$.

66 Nogueira Alcalá, Humberto: Derechos fundamentales y garantías constitucionales. Tomo I. Santiago de Chile, Librotecnia, 2007, pp. 88 y ss.

67 Tribunal Constitucional: Requerimiento de inaplicabilidad por inconstitucionalidad presentado por Sheila Hasbuin Bernier respecto del inciso tercero del artículo 38 y artículo 38 bis de la Ley $N^{o} 18.933$, al que se acumuló el Rol No 2020-11, requerimiento presentado por Julio Francisco Javier Fuenzalida Asmussen respecto de las mismas normas. Rol No 1856-10 (2020-11)-INA. Sentencia de fecha 2 de mayo de 2012. Voto por acoger el requerimiento, considerando $26^{\circ}$.

68 Tribunal Constitucional: Requerimiento de inaplicabilidad por inconstitucionalidad presentado por Sheila Hasbún Bernier respecto del inciso tercero del artículo 38 y artículo 38 bis de la Ley $N^{o} 18.933$, al que se acumuló el Rol No 2020-11, requerimiento presentado por Julio Francisco Javier Fuenzalida Asmussen respecto de las mismas normas. Rol No 1856-10 (2020-11)-INA. Sentencia de fecha 2 de mayo de 2012. Voto por acoger 


\section{Uso del derecho europeo como ejemplo o reforzamiento de la argumentación}

El voto por acoger el requerimiento de inaplicabilidad por inconstitucionalidad de manera muy interesante utiliza lo que él denomina Derecho comparado. Curiosamente se habla de Derecho comparado porque, evidentemente, la referencia no se hace a un derecho estatal, sino que a un derecho supranacional como es el Derecho europeo. Así, se menciona: "la Directiva 93/13, de cinco de abril de 1993, de la Comunidad Europea, sobre cláusulas abusivas en los contratos celebrados con consumidores, vinculante para todos los países de la Comunidad, consagra este principio tutelar declarando que una cláusula redactada previamente sin que el consumidor haya podido influir sobre su contenido, es abusiva cuando causa un desequilibrio importante entre los derechos y obligaciones que se derivan del contrato en detrimento del consumidor (artículo $3^{\circ}$ ). Tales cláusulas no negociadas, impuestas al consumidor en contratos con proveedores o prestadores dentro de su propia actividad, no obligan al consumidor y el contrato sigue siendo obligatorio para las partes en los mismos términos, siempre que las cláusulas abusivas no afecten a su existencia (artículo $6^{\circ}$ );"69.

Con todo, la mención anterior sirve para introducir someramente el tema del diálogo judicial y del uso del derecho extraestatal como ejemplo o como reforzamiento. En este caso el uso del derecho supranacional sirve como ejemplo que permite "darle músculos" a la argumentación del voto por acoger ${ }^{70}$.

\section{Métodos de interpretación constitucional vs. Interpretación en derechos humanos}

Por último, queremos destacar el uso que se hace de principios de interpretación constitucional en el voto por el rechazo del requerimiento. Así, se señala que "los Ministros que suscriben este voto no pueden dejar adicionalmente de tener

\footnotetext{
el requerimiento, considerando 42º Ferrajoli, Luigi: Principia Iuris, Teoría del Derecho y de la Democracia. Editorial Trotta, Madrid, 2011, pp. 246-247.

69 Tribunal Constitucional: Requerimiento de inaplicabilidad por inconstitucionalidad presentado por Sheila Hasbún Bernier respecto del inciso tercero del artículo 38 y artículo 38 bis de la Ley $N^{o} 18.933$, al que se acumuló el Rol No 2020-11, requerimiento presentado por Julio Francisco Javier Fuenzalida Asmussen respecto de las mismas normas. Rol No 1856-10 (2020-11)-INA. Sentencia de fecha 2 de mayo de 2012. Voto por rechazar el requerimiento, considerando $23^{\circ}$.

70 SÁz Arnaiz, Alejandro: "La Carta de los Derechos Fundamentales de la Unión Europea y los ordenamientos nacionales: ¿qué hay de nuevo?”, en Cuadernos de Derecho Público, No 13 (2001), pp. 153-170.
} 
en consideración las consecuencias, para el caso concreto, que podría ocasionar una declaración de inaplicabilidad como la impetrada en estos autos. En efecto, como lo ha sostenido esta Magistratura, "constituye un principio elemental de prudencia constitucional el que el Tribunal Constitucional debe abstenerse de declarar la inaplicabilidad por inconstitucionalidad de una norma en aquellos casos en que ello pudiera engendrar una lesión de mayor envergadura constitucional"'1. Vale la pena contrastar este principio de interpretación constitucional o de prudencia constitucional al que recurre el voto por el rechazo para justificar su decisión, frente a otros principios de derechos humanos que brillan por su omisión. Por cierto, hay principios de derechos humanos, algunos de ellos analizados en el voto por acoger que enfrentados a principios de interpretación constitucional deberían primar o al menos hacerse valer en el razonamiento constitucional. El lector de este voto podría válidamente preguntarse: qué ocurre con el principio de igualdad, con el principio de universalidad, con el principio de indivisibilidad, con el principio pro-homine, con el principio de efectividad de los derechos humanos, con el principio de optimización, con el principio de interpretación conforme a los derechos humanos, etc.

Desde el punto de vista de los derechos de las personas -los derechos humanosa quienes protege la Constitución y sirve el Estado, conviene recordar algunos criterios interpretativos que ha desarrollado evolutivamente la jurisprudencia del Tribunal Constitucional. Así, el mismo Tribunal ha reconocido la existencia de la Constitución material -por contraposición a aquella Constitución formal propia de la primera mitad del siglo pasado- $y$ ha repetido incansablemente que los derechos humanos son los portadores por excelencia y los recipientes de los valores y principios que identifican la parte material de la Constitución contemporánea. En efecto, los jueces constitucionales han sostenido reiteradamente que deben "limitar su pronunciamiento a la conformidad o disconformidad del acto de cuyo control se trate, con los principios, valores y normas constitucionales" 72 .

71 Tribunal Constitucional: Requerimiento de inaplicabilidad por inconstitucionalidad presentado por Sheila Hasbún Bernier respecto del inciso tercero del artículo 38 y artículo 38 bis de la Ley No 18.933, al que se acumuló el Rol No 2020-11, requerimiento presentado por Julio Francisco Javier Fuenzalida Asmussen respecto de las mismas normas. Rol No 1856-10 (2020-11)-INA. Sentencia de fecha 2 de mayo de 2012. Voto por rechazar el requerimiento, considerando $11^{\circ}$; Vid. STC Rol No 616/2007.

72 Tribunal Constitucional de Chile: Requerimiento de inaplicabilidad presentado por S. C.M. Virginia respecto del artículo 96 del Código de Minería en el proceso sobre prescripción extintiva de la acción de nulidad de pertenencia minera Rol No 107-03, caratulada Sociedad Quimica y Minera de Chile S.A. con S.C.M. Virginia, seguida ante el Juzgado de Letras de María Elena y en tramitación ante la Corte Suprema, bajo el Rol No 6213-05. Rol No 608-06. Sentencia de fecha 2 de octubre de 2007. Considerando $13^{\circ}$. 
Desde la perspectiva de la interpretación, se hace necesario recordar que al Tribunal Constitucional se le ha encomendado "la interpretación definitiva e inapelable de la Constitución, interpretación que debe desarrollarse en forma integral, esto es, considerando tanto la letra como los valores, principios y espíritu de la Carta Fundamental, a fin de asegurar la vigencia efectiva de la supremacía constitucional, que es la que garantiza, en definitiva, la eficacia del Estado constitucional de Derecho y el respeto de los derechos fundamentales de las personas"73.

Junto con lo anterior, es importante para valorar el pronunciamiento de los jueces constitucionales en la sentencia analizada, considerar su jurisprudencia en materia interpretativa. Los jueces constitucionales han sostenido que "es una norma de lógica interpretación constitucional muy aconsejable de seguir en situaciones como la que enfrentamos, aquella que nos previene que en los casos en que las palabras o las expresiones de un precepto puedan tener un significado o un alcance distinto, siempre debe preferirse aquel que mejor se aviene con la finalidad perseguida por la norma, obtenida del contexto de la Constitución o de los antecedentes que se tuvieron en vista para establecerla, cuidando siempre que ella armonice con principios tan fundamentales como los contenidos en los artículos $1^{\circ}, 4^{\circ}, 5^{\circ}, 6^{\circ}$ y $7^{\circ}$ de nuestra Carta Fundamental que [...] son preceptos normativos que reflejan la filosofía que inspira nuestra Constitución" 74 . En efecto, "el artículo $1^{\circ}$ de la Carta Fundamental constituye uno de los preceptos más fundamentales en que se basa la institucionalidad, ya que por su profundo y rico contenido doctrinario refleja la filosofía que inspira nuestra Constitución y orienta al intérprete en su misión de declarar y explicar el verdadero sentido y alcance del resto de la preceptiva constitucional"75. Y, luego, el Tribunal Constitucional concluye sobre este aspecto de la Constitución que "la Carta Fundamental después de establecer esta norma rectora y vital va encarnándola en preceptos concretos: enumera los derechos que se les asegura a las personas $[\ldots . .]^{\prime \prime 76}$.

73 Tribunal Constitucional de Chile: Requerimiento de inconstitucionalidad de la Resolución Exenta No 584 (Ministerio de Salud), fechada el 1 de septiembre de 2006, la cual aprueba Normas Nacionales sobre Regulación de la Fertilidad. Rol No 591-06. Sentencia de fecha 11 de enero de 2007. Considerando $3^{\circ}$.

74 Tribunal Constitucional de Chile: Requerimiento respecto del Decreto Supremo No 20 del Ministerio Secretaría General de la Presidencia, publicado en el Diario Oficial de 12 de abril de 2001. Rol No 325. Sentencia de fecha 26 de junio de 2001. Considerando $12^{\circ}$.

75 Tribunal Constitucional de Chile: Control de constitucionalidad respecto del Proyecto de Ley Orgánica Constitucional sobre Votaciones Populares y Escrutinios. Rol No 53-88. Sentencia de fecha 5 de abril de 1988. Considerando $12^{\circ}$.

76 Tribunal Constitucional de Chile: Control de constitucionalidad respecto del Proyecto de Ley Orgánica Constitucional sobre Votaciones Populares y Escrutinios. Rol No 53-88. Sentencia de fecha 5 de abril de 1988. Considerando $13^{\circ}$. 
A mayor abundamiento, sirva recordar la propia jurisprudencia del Tribunal Constitucional, que ha señalado que "se infiere con nitidez que el ordenamiento institucional estructurado por la Constitución de 1980 descansa sobre ciertos principios y valores básicos, entre los cuales, cabe señalar, por su íntima vinculación con el problema que se analiza, los siguientes: la libertad del hombre, que los derechos fundamentales de la persona humana son anteriores y superiores al Estado y a la Constitución, razón por la cual ésta no los crea sino que los 'reconoce y asegura'; que el Estado en cumplimiento de su finalidad propia, cual es promover el bien común, debe darles segura y eficaz protección debiendo destacarse, en la especie, 'la seguridad y certeza jurídica'; que el ejercicio de la soberanía que se realiza por el pueblo y por las autoridades que la Constitución establece reconoce como limitación el respeto a los derechos esenciales que emanan de la naturaleza humana [...]"77. Luego, los jueces constitucionales afirman que "todos estos principios se encarnan en disposiciones concretas de la Carta Fundamental como lo son, entre otros, los artículos $1^{\circ}, 4^{\circ}, 5^{\circ}$, inciso segundo, y 19, en especial su número 3, inciso séptimo"78. Y, concluyen este excelente razonamiento señalando que "estos preceptos no son meramente declarativos sino que constituyen disposiciones expresas que obligan a gobernantes y gobernados tanto en sí mismas, como también, en cuanto normas rectoras y vitales que coadyuvan a desentrañar el verdadero sentido y espíritu del resto de las disposiciones de la Constitución"79.

El contenido superior que identifica las normas materiales de carácter constitucional, que a la sazón es la dignidad humana, la libertad y la igualdad y los derechos que de ella emanan, ha sido reconocido por el Tribunal Constitucional. El contenido superior de las normas de carácter constitucional, en general reflejadas en aquellas normas que protegen los derechos humanos de las personas y grupos, conducen a una interpretación que las hace prevalecer en el ordenamiento. Desde este punto de vista, la propia jurisprudencia de este Tribunal ha afirmado que no puede dejar de ejercer sus competencias constitucionales cuando se denuncian

77 Tribunal Constitucional: Requerimiento formulado por el ministro del Interior, en virtud del artículo 82 de la Constitución, para que se declare la responsabilidad del señor Clodomiro Almeyda Medina por infracción al artículo $8^{\circ}$ de la Constitución. Rol No 46-87. Sentencia de fecha 21 de diciembre de 1987. Considerando $19^{\circ}$.

78 Tribunal Constitucional: Requerimiento formulado por el ministro del Interior, en virtud del artículo 82 de la Constitución, para que se declare la responsabilidad del señor Clodomiro Almeyda Medina por infracción al artículo $8^{\circ}$ de la Constitución. Rol No 46-87. Sentencia de fecha 21 de diciembre de 1987. Considerando $20^{\circ}$.

79 Tribunal Constitucional: Requerimiento formulado por el ministro del Interior, en virtud del artículo 82 de la Constitución, para que se declare la responsabilidad del señor Clodomiro Almeyda Medina por infracción al artículo $8^{\circ}$ de la Constitución. Rol No 46-87. Sentencia de fecha 21 de diciembre de 1987. Considerando $21^{\circ}$. 
actos que atentan contra la Constitución, "[a]ún más si se imputan a ella graves vicios de constitucionalidad que involucran, entre otros, valores y principios constitucionales fundamentales como la dignidad intrínseca de la persona humana, instituida como base esencial y primigenia de nuestro sistema constitucional por el artículo $1^{\circ}$ de la Ley Suprema" 80 .

En este contexto, cabe absolutamente tener presente lo que los jueces constitucionales han afirmado, en el sentido de que a dicho tribunal "en cuanto órgano del Estado, le asiste el deber de respetar y promover los derechos esenciales que emanan de la naturaleza humana reconocidos por la Constitución y por los tratados internacionales ratificados por Chile y que se encuentren vigentes, tal como ordena el artículo 50, inciso segundo, de la Carta Fundamental" 81. Asimismo, cabe mencionar otro principio de interpretación constitucional muy relevante, en el sentido de que "no es dable suponer que la Carta Política incluya en su texto normas superfluas o reiterativas que lejos de regular en forma clara la convivencia política y pacífica de un pueblo en sociedad, confunda o dé cabida a interpretaciones que permiten vulnerar la esencia de los principios y valores en que ella descansa, o hacer ambiguo o confuso lo que para el Constituyente es claro e inequívoco. [...] La razón de ser de esta regla, en el ámbito constitucional, es muy simple: es inadmisible aceptar que la Constitución contenga normas sin sentido, sin aplicación práctica, reiterativas o sin una justificación razonable dentro del sistema diseñado por el Constituyente" 82 .

Por último, sin duda que el principal principio de interpretación en materia de derechos humanos corresponde al principio pro-homine, el cual ha sido asumido en reiteradas ocasiones por el Tribunal Constitucional. En efecto, se ha dicho que "para dilucidar el conflicto constitucional planteado y ante la evidencia de estar estos jueces frente a una duda razonable, ha de acudirse a aquellos criterios hermenéuticos desarrollados por la teoría de los derechos fundamentales, por ser

80 Tribunal Constitucional de Chile: Requerimiento de inconstitucionalidad de la Resolución Exenta No 584 (Ministerio de Salud), fechada el 1 de septiembre de 2006, la cual aprueba Normas Nacionales sobre Regulación de la Fertilidad. Rol No 591-06. Sentencia de fecha 11 de enero de 2007. Considerando $3^{\circ}$.

81 Tribunal Constitucional de Chile: Requerimiento de inconstitucionalidad deducido en contra de algunas disposiciones de las "Normas Nacionales sobre Regulación de la Fertilidad", aprobadas por el Decreto Supremo No 48, de 2007, del Ministerio de Salud. Rol No 740-07. Sentencia de fecha 18 de abril de 2008. Considerando 11

82 Tribunal Constitucional de Chile: Requerimiento de diputados acerca del proyecto de ley que establece un sistema de elecciones primarias para determinar el candidato a la presidencia de la República. Rol No 279-98. Sentencia de fecha 6 de octubre de 1998. Considerando $3^{\circ}$. Tribunal Constitucional de Chile: Requerimiento respecto del Decreto Supremo No 20 del Ministerio Secretaría General de la Presidencia publicado en el Diario Oficial de 12 de abril de 2001. Rol No 325. Sentencia de fecha 26 de junio de 2001. Considerando $10^{\circ}$. 
ésa la materia comprometida en el presente requerimiento. En tal sentido, parece ineludible tener presente el principio "pro-homine" o "favor libertatis" definido en la jurisprudencia de la Corte Interamericana de Derechos Humanos de la siguiente forma: 'Entre diversas opciones se ha de escoger la que restringe en menor escala el derecho protegido (...) debe prevalecer la norma más favorable a la persona humana' (Opinión Consultiva 5, 1985)"83.

El voto por el rechazo omite considerar todos estos principios de interpretación en materia de derechos humanos - que es de lo que trata esta sentencia- amparándose básicamente en un principio elemental de prudencia constitucional.

\section{REFLEXIONES FINALES}

Esta sentencia es ejemplar por varias razones. En primer lugar, porque muestra las dinámicas en las que se ve envuelta la jurisdicción constitucional a propósito del ejercicio de su facultad de judicial review. Argumentos de prudencia constitucional que conducen a una actuación restrictiva impiden que el Tribunal Constitucional acoga un requerimiento de inaplicabilidad por inconstitucionalidad aplicando para ello toda su rica doctrina en materia de derechos sociales y contratos de salud, en particular, en la esfera de los derechos a la protección de la salud y de la seguridad social concordados con el derecho a la igualdad.

La situación del empate condujo finalmente al rechazo de la acción de inaplicabilidad. Quizá, a modo de reflexión, valdría la pena preguntarse si los ciudadanos se merecen esta nivelación jurisdiccional. Claro, de acuerdo con nuestro diseño normativo, en estos casos, un empate equivale a una derrota, pero, ¿es realmente una derrota cuando igual número de jueces constitucionales proporciona, al menos, tan abundantes y convincentes argumentos como la posición contraria?

Justamente nuestra atención se centró, en este breve examen, en esos abundantes y convincentes argumentos por acoger el requerimiento, que, además, desarrollan y hacen evolucionar las enseñanzas del Tribunal en materias tan necesarias como la de los derechos sociales. Así, el voto por acoger el requerimiento contribuye a precisar cuáles son los contenidos constitucionales del derecho a la protección de la salud y su delimitación y, además, cuáles son las características del contrato de salud, que -como se sabe- es de orden público y de jerarquía constitucional por los bienes públicos que ampara. Igualmente, y de manera

83 Tribunal Constitucional de Chile: Requerimiento de inconstitucionalidad deducido en contra de algunas disposiciones de las "Normas Nacionales sobre Regulación de la Fertilidad", aprobadas por el Decreto Supremo No 48 , de 2007, del Ministerio de Salud. Rol No 740-07. Sentencia de fecha 18 de abril de 2008. Considerando 66. 
muy interesante, este voto ahonda en la relación entre la libertad contractual y el principio constitucional de igualdad, y, particularmente, reconoce en propiedad el fenómeno de constitucionalización del Derecho civil. No menos importante, el voto por acoger desarrolla aun más una tendencia que ya había comenzado el Tribunal Constitucional, años atrás, por ejemplo, en el caso de Silvia Peña Wassaff, relativa a la justiciabilidad de los derechos sociales y a la eficacia entre particulares de los derechos fundamentales. Esta sentencia nos parece muy relevante en cuanto continúa con esta línea de pensamiento, y profundiza esta idea, que muchas veces no es muy bien comprendida o aceptada, referente a la penetración del Derecho constitucional, especialmente, los derechos fundamentales, en el ámbito de las relaciones jurídico-privadas. Lo que resta por ver es si esta tendencia refleja un proceso meramente formal o implica consideraciones de fondo, id est, materiales, acerca de la irradiación de los valores y principios constitucionales hacia el resto del ordenamiento estatal. 